\title{
HIF-1 $\alpha /$ GPER signaling mediates the expression of VEGF induced by hypoxia in breast cancer associated fibroblasts (CAFs)
}

Ernestina Marianna De Francesco', Rosamaria Lappano', Maria Francesca Santolla', Stefania Marsico', Arnaldo Caruso $^{2}$ and Marcello Maggiolini ${ }^{*}$

\begin{abstract}
Introduction: Carcinoma-associated fibroblasts (CAFs) play a pivotal role in cancer progression by contributing to invasion, metastasis and angiogenesis. Solid tumors possess a unique microenvironment characterized by local hypoxia, which induces gene expression changes and biological features leading to poor outcomes. Hypoxia Inducible Factor 1 (HIF-1) is the main transcription factor that mediates the cell response to hypoxia through different mechanisms that include the regulation of genes strongly associated with cancer aggressiveness. Among the HIF-1 target genes, the G-protein estrogen receptor (GPER) exerts a stimulatory role in diverse types of cancer cells and in CAFs.
\end{abstract}

Methods: We evaluated the regulation and function of the key angiogenic mediator vascular endothelial growth factor (VEGF) in CAFs exposed to hypoxia. Gene expression studies, Western blotting analysis and immunofluorescence experiments were performed in CAFs and breast cancer cells in the presence of cobalt chloride $\left(\mathrm{CoCl}_{2}\right)$ or cultured under low oxygen tension $\left(2 \% \mathrm{O}_{2}\right)$, in order to analyze the involvement of the HIF-1 $\alpha /$ GPER signaling in the biological responses to hypoxia. We also explored the role of the HIF-1 $\alpha / G P E R$ transduction pathway in functional assays like tube formation in human umbilical vein endothelial cells (HUVECS) and cell migration in CAFs.

Results: We first determined that hypoxia induces the expression of HIF-1 $\alpha$ and GPER in CAFs, then we ascertained that the HIF-1 $\alpha /$ GPER signaling is involved in the regulation of VEGF expression in breast cancer cells and in CAFs exposed to hypoxia. We also assessed by ChIP assay that HIF-1 $\alpha$ and GPER are both recruited to the VEGF promoter sequence and required for VEGF promoter stimulation upon hypoxic condition. As a biological counterpart of these findings, conditioned medium from hypoxic CAFs promoted tube formation in HUVECs in a HIF-1 $\alpha /$ GPER dependent manner. The functional cooperation between HIF-1 $\alpha$ and GPER in CAFs was also evidenced in the hypoxia-induced cell migration, which involved a further target of the HIF-1 $\alpha /$ GPER signaling like connective tissue growth factor (CTGF).

Conclusions: The present results provide novel insight into the role elicited by the HIF-1 $\alpha /$ GPER transduction pathway in CAFs towards the hypoxia-dependent tumor angiogenesis. Our findings further extend the molecular mechanisms through which the tumor microenvironment may contribute to cancer progression.

\section{Introduction}

The cooperative interactions among tumor cells and reactive stroma strongly contribute to cancer development and progression [1,2]. Cancer-associated fibroblasts (CAFs)

\footnotetext{
* Correspondence: marcellomaggiolini@yahoo.it

'Department of Pharmacy, Health and Nutritional Sciences, University of Calabria, 87036 Rende (Cosenza), Italy

Full list of author information is available at the end of the article
}

have been indicated as the main cellular component of the tumor microenvironment involved in cancer initiation, invasion and metastasis [3-5]. In breast malignancies, CAFs exert a pivotal role in tumor progression and resistance to therapeutics through multiple mechanisms, including the stimulation of new blood vessels [6], mainly generated by a hypoxic tumor microenvironment [7-9]. Indeed, mechanisms of cell sensing and adaptation to

\section{Biomed Central}


stressful environments are activated within the hypoxic tumor mass, leading to the growth and aggressiveness of malignant cells [10]. The transcription factor Hypoxia Inducible Factor 1 (HIF-1) primarily mediates the cell responses to a low oxygen tension playing a crucial role in cancer development [11,12]. In particular, HIF-1 activates a signaling transduction network which drives the adaptation of tumor cells to hypoxic conditions towards a more aggressive cancer phenotype [13]. HIF-1 is a heterodimeric protein composed of the hypoxia-inducible $\alpha$ subunit and the constitutively expressed $\beta$ subunit [14]. HIF-1 $\alpha$ and HIF-1 $\beta$ dimerize upon exposure to hypoxia, generating a complex which binds to the hypoxia-responsive elements (HREs) located within the promoter region of target genes [15]. In this regard, it has been shown that HIF-1 is a leading regulator of tumor angiogenesis following hypoxia, as it regulates the expression of several pro-angiogenic factors, like the vascular endothelial growth factor (VEGFA) [16-18]. Recently, we discovered a further HIF-1-regulated gene, the G-protein estrogen receptor (GPER), which contributes to the adaptation to a low oxygen environment in breast cancer cells and in cardiomyocytes [19]. In particular, we found that the cooperation between GPER and HIF-1 $\alpha$ upon exposure to hypoxia leads to the up-regulation of the Connective Tissue Growth Factor (CTGF) [19], which is a target gene of both HIF-1 $\alpha[19,20]$ and GPER [21,22]. Surprisingly, we also assessed that in CAFs derived from breast cancer malignancies GPER acts as a transcription factor promoting the expression of genes involved in cell proliferation and migration [23]. On the basis of these data, GPER-mediated functions may be included among the mechanisms driving the biological responses to hypoxia within the tumor microenvironment.

Considering that hypoxia regulates HIF-1 $\alpha$-dependent expression of both GPER and VEGF in different model systems, in the present study we aimed to evaluate the potential involvement of GPER in the expression and function of VEGF in CAFs and breast cancer cells. In this regard, we demonstrate that HIF-1 $\alpha /$ GPER signaling mediates the up-regulation of VEGF as well as the endothelial tube formation, suggesting that this transduction pathway may be involved in the intricate stimulatory responses to hypoxia within the cancer stroma. Our data may open new perspectives towards innovative therapeutic strategies targeting the breast cancer microenvironment.

\section{Materials and methods Reagents}

Cobalt chloride $\left(\mathrm{CoCl}_{2}\right)$ and the ROS scavenger N-acetylL-cysteine (NAC) were purchased from Sigma-Aldrich Srl (Milan, Italy). PD98059 (PD) was obtained from Calbiochem (Milan, Italy). Human CTGF was purchased from MBL International Corporation, distributed by
Eppendorf, (Milan, Italy). Human VEGF was purchased from Peprotech (Rocky Hill, NJ, USA). All compounds were dissolved in DMSO, except NAC, CTGF and VEGF, which were solubilized in water.

\section{Ethics statement}

All procedures conformed to the Helsinki Declaration for the research on humans. The experimental research has been performed with the ethical approval provided by the Ethics Committee of the Regional Hospital in Cosenza, Italy.

\section{Cell cultures}

The SkBr3 breast cancer cells were maintained in RPMI1640 (Invitrogen, Milan, Italy) without phenol red, supplemented with $10 \%$ fetal bovine serum (FBS) and $100 \mu \mathrm{g} / \mathrm{ml}$ penicillin/streptomycin. The murine cardiomyocyte-like cell line HL-1 was kindly provided by Dr. William C. Claycomb (Louisiana State University Medical Center, New Orleans, LA, USA). In particular, the HL-1 cell line was established from a mouse atrial cardiomyocyte tumor excised from an adult female Jackson Laboratory-inbred C57BLy6J mouse (Jackson Laboratory, Bar Harbor, Maine, USA) [24]. HL-1 cells were cultured according to the published protocol [24] in Claycomb medium (JRH Biosciences, Sigma-Aldrich Srl, Milan, Italy) supplemented with 10\% FBS (JRH Bioscience, Sigma-Aldrich Srl), 100 $\mu \mathrm{g} / \mathrm{ml}$ penicillin/streptomycin (Invitrogen, Milan, Italy), $0.1 \mathrm{mM}$ norepinephrine (Sigma-Aldrich Srl) and $2 \mathrm{mM} \mathrm{L-}$ glutamine (Invitrogen). Human umbilical vein endothelial cells (HUVECs) were seeded on collagen-coated flasks (Sigma-Aldrich Srl) and cultured in endothelial growth medium (EGM) (Lonza, Milan, Italy), supplemented with $5 \%$ FBS (Lonza, Milan, Italy). All cell lines were grown in a $37^{\circ} \mathrm{C}$ incubator with $5 \% \mathrm{CO}_{2}$. For hypoxic stimulation, cells were treated with $\mathrm{CoCl}_{2}$ or cultured in the presence of low oxygen tension $\left(2 \% \mathrm{O}_{2}\right)$ in a HeraCell incubator (ThermoScientific-Heraeus, Milan, Italy). Cells were switched to medium without serum the day before experiments.

\section{Isolation, cultivation and characterization of CAFs}

CAFs were extracted from six invasive mammary ductal carcinomas obtained from mastectomies as previously described [23]. Signed informed consent from all the patients and IRB approval were obtained. In particular, tissues obtained were cut into smaller pieces (1 to $2 \mathrm{~mm}$ diameter), placed in digestion solution (400 IU collagenase, 100 IU hyaluronidase and 10\% FBS, containing antibiotics and antimycotics solution) and incubated overnight at $37^{\circ} \mathrm{C}$. Cells were then separated by differential centrifugation at $90 \times \mathrm{g}$ for two minutes. The supernatant containing fibroblasts were centrifuged at $485 \times \mathrm{g}$ for eight minutes, the pellet obtained was suspended in fibroblasts 
growth medium (Medium 199 and Ham's F12 mixed 1:1 and supplemented with $10 \% \mathrm{FBS}$ and $1 \%$ penicillin) and cultured at $37^{\circ} \mathrm{C}, 5 \% \mathrm{CO}_{2}$. In each patient, a second population of fibroblasts was isolated from a noncancerous breast tissue at least $2 \mathrm{~cm}$ from the outer tumor margin. CAFs and fibroblasts were then expanded into two $15-\mathrm{cm}$ Petri dishes and stored as cells passaged for two to three population doublings within a total 7 to 10 days after tissue dissociation. We used CAFs and fibroblasts passaged for up to five population doublings for subsequent experiments to minimize clonal selection and culture stress, which could occur during extended tissue culture. Primary cells cultures of breast fibroblasts were characterized by immunofluorescence. Briefly, cells were incubated with human anti-vimentin (V9) and human anti-cytokeratin 14 (LL001), all antibodies were from Santa Cruz Biotechnology, DBA (Milan, Italy). In order to assess fibroblast activation, we used anti-fibroblast activated protein $\alpha$ (FAP $\alpha$ ) antibody (H-56) purchased from Santa Cruz Biotechnology, DBA (Milan, Italy) (data not shown). All experiments were performed in each CAF population obtained from six patients. Data presented were obtained in CAFs derived from one patient; however, results similar to those shown were found in CAFs derived from the other five patients.

\section{Gene reporter assays}

The $2.6 \mathrm{~kb} V E G F$ promoter-luciferase construct containing full-length VEGF promoter sequence $(22,361$ to +298 bp relative to the transcription start site) used in luciferase assays was a kind gift from Dr. Pal Soumitro (Harvard Medical School, Boston, MA, USA). CAFs or SkBr3 cells $\left(1 \times 10^{5}\right)$ were plated into 24 -well dishes with $500 \mu \mathrm{L} /$ well culture medium containing $10 \%$ FBS and transfected for $24 \mathrm{~h}$ with control shRNA, shHIF-1 $\alpha$ or shGPER. Next, a mixture containing $0.5 \mu \mathrm{g}$ of reporter plasmid and $10 \mathrm{ng}$ of pRL-TK was transfected within cells. Transfections were performed using FuGENE 6 reagent as recommended by the manufacturer (Roche Diagnostics, Milan, Italy). After $8 \mathrm{~h}$, cells were treated with $100 \mu \mathrm{M} \mathrm{CoCl} 2$ or exposed to low oxygen $\left(2 \% \mathrm{O}_{2}\right)$ for $12 \mathrm{~h}$ in serum-free medium. Luciferase activity was measured with the Dual Luciferase Kit (Promega, Milan, Italy) normalized to the internal transfection control provided by Renilla luciferase activity. The normalized relative light unit values obtained from cells treated with vehicle were set as one-fold induction, from which the activity induced by treatments was calculated.

\section{Gene expression studies}

Total RNA was extracted from cell cultures using the Trizol commercial kit (Invitrogen) according to the manufacturer's protocol. RNA was quantified spectrophotometrically and quality was checked by electrophoresis through agarose gels stained with ethidium bromide. Only samples that were not degraded and showed clear $18 \mathrm{~S}$ and $28 \mathrm{~S}$ bands under ultraviolet light were used for RT-PCR. Total cDNA was synthesized from the RNA by reverse transcription using the murine leukemia virus reverse transcriptase (Invitrogen) following the protocol provided by the manufacturer. The expression of selected genes was quantified by both real-time RT-PCR using Step One ${ }^{\circledR}$ sequence detection system (Applied Biosystems, Inc., Milan, Italy) and semiquantitative RT-PCR [25]. Gene-specific primers were designed using Primer Express version 2.0 software (Applied Biosystems, Inc.) and are as follows: $H I F-1 \alpha$ Fwd: 5'-TGCATCTCCATCTTCTACCCAAGT-3' and Rev: 5'-CCGACTGTGAGTGCCACTGT-3'; GPER Fwd: 5'ACACACCTGGGTGGACACAA-3' and Rev: 5'-GGAGCCAGAAGCCACATCTG-3'; CTGF Fwd: 5'-ACCTGTGGGATGGGCATCT-3' and Rev: 5'-CAGGCGGC TCTGCTTCTCTA-3'; VEGF (human): Fwd: 5'- TGCAGATTATGCGGATCAAACC-3' and Rev: 5' - TGCATTCACATTTGTTGTGCTGTAG-3'; VEGF (mouse) Fwd: 5'- GGAGATCCTTCGAGGAGCACTT-3' and Rev: 5'- GGCGATTTA GCAGCAGATATAAGAA-3'; $18 \mathrm{~S}$ (human, mouse) Fwd: 5'-GGCGTCCCCCAACTTCTTA3' and Rev: 5'- GGGCATCACAGACCTGTTATT -3. The ribosomal protein $18 S$ was used as a control gene to obtain normalized values.

For semiquantitative PCR, primers were as follows: HIF-1 $\alpha$ Fwd: 5' - GCTGATTTGTGAACCCAT TC-3' and Rev: 5'- CTGTACTGTCCTGTGGTGAC-3'; GPER Fwd: 5' - CTGGGGAGTTTCCTG TCTGA -3' and Rev: 5'-GCTTGGGAAGTCACATCCAT-3'; CTGF Fwd: 5'-ATGGCATGAAGCCAGAGAGT-3' and Rev: 3'-GGTCAGTGAGCACGCTAAAA-3'; VEGF (human) Fwd: 5'-GAGCTTCAGGACATTGCTGT-3' and Rev: 5'-AGGAAGGTCAACCACTCACA-3'; VEGF (mouse) Fwd: 5'-CGTGTAAATGTTCCTGCAAA-3' and Rev: 5'-CGTGTAAATGTTCCTGCAAA-3'; 36B4 (human) Fwd: 5'CTCAACATCTCССССТTCTC-3' and Rev: 5'-CAAATCCCATATCCTCGTCC-3'; GAPDH (mouse) Fwd: 5'-ACCACAGTCCATGCCATCAC-3' and Rev: 5'-TCCACCACCCTGTTGCTGTA-3'. 36B4 and GAPDH were used as control genes to obtain normalized values.

\section{Western blot analysis}

To prepare lysates, CAFs were washed in phosphatebuffered saline (PBS) and solubilized with $50 \mathrm{mM}$ Hepes solution, pH 7.4, containing $1 \%(\mathrm{v} / \mathrm{v})$ Triton X-100, 4 $\mathrm{mM}$ EDTA, $1 \mathrm{mM}$ sodium fluoride, $0.1 \mathrm{mM}$ sodium orthovanadate, $2 \mathrm{mM}$ phenylmethanesulfonyl fluoride (PMSF), $10 \mu \mathrm{g} / \mathrm{ml}$ leupeptin and $10 \mu \mathrm{g} / \mathrm{ml}$ aprotinin. Protein concentrations in the supernatant were determined according to the Bradford method. Cell lysates (10 to $50 \mu \mathrm{g}$ of protein) were electrophoresed through a 
reducing SDS/10\% (w/v) polyacrylamide gel and electroblotted onto a nitrocellulose membrane. Membranes were blocked and incubated with primary polyclonal IgG antibody for HIF-1 $\alpha$ (R\&D Systems, Inc., Celbio, Milan, Italy), GPER (N-15), CTGF (L-20), phosphorylated ERK1/2 (E-4), ERK2 (C-14), $\beta$-actin (C2), b-tubulin (H-235-2) and appropriate secondary HRP-conjugated antibodies, all purchased from Santa Cruz Biotechnology (DBA). The levels of proteins and phosphoproteins were detected with horseradish peroxidase-linked secondary antibodies and revealed using the ECL ${ }^{\circledR}$ System (GE Healthcare, Milan, Italy).

\section{Gene silencing experiments}

Cells were plated onto $10 \mathrm{~cm}$ dishes and transfected for 24 $\mathrm{h}$ before treatments with a control vector or an independent shRNA sequence for each target gene using Fugene6 (Roche Diagnostics). The shRNA plasmid for HIF- $1 \alpha$ and the respective control plasmids were purchased from SABioscience Corporation (Frederick, MD, USA). The silencing of GPER expression was obtained by the construct which we have previously described and used [26].

\section{Immunofluorescence microscopy}

Fifty percent confluent cultured CAFs, SkBr3 and HL-1 cells grown on coverslips were serum-deprived for $24 \mathrm{~h}$ and treated for $12 \mathrm{~h}$ with $100 \mu \mathrm{M} \mathrm{CoCl}$ or exposed for $12 \mathrm{~h}$ to low oxygen tension $\left(2 \% \mathrm{O}_{2}\right)$. Then cells were fixed in $4 \%$ paraformaldehyde, permeabilized with $0.2 \%$ Triton X-100, washed three times with PBS and incubated overnight with a mouse primary antibody against VEGF (C-1) (Santa Cruz Biotechnology, DBA). After incubation, the slides were extensively washed with PBS and incubated with 4',6-Diamidino-2-phenylindole dihydrochloride (DAPI), (1:1,000), (Sigma-Aldrich Srl) and donkey anti-mouse IgG-FITC (1:300; purchased from Alexa Fluor, Invitrogen). For knockdown experiments, cells were previously transfected for $24 \mathrm{~h}$ with shHIF- $1 \alpha$ or shGPER and respective negative control plasmids (as described above) and then treated for $12 \mathrm{~h}$ with $100 \mu \mathrm{M}$ $\mathrm{CoCl}_{2}$, or cultured under hypoxia as indicated. Leica AF6000 Advanced Fluorescence Imaging System supported by quantification and image processing software Leica Application Suite Advanced Fluorescence (Leica Microsystems CMS, GbH Mannheim, Germany) were used for experiment evaluation.

\section{Chromatin Immunoprecipitation (ChIP) assay}

CAFs were grown in $10-\mathrm{cm}$ dishes to 60 to $70 \%$ confluence, serum deprived for $24 \mathrm{~h}$ and then treated with vehicle or $100 \mu \mathrm{M} \mathrm{CoCl}_{2}$ for $1 \mathrm{~h}$. Thereafter, cells were cross-linked with $1 \%$ formaldehyde and sonicated. Supernatants were immuno-cleared with salmon DNA/ protein A-agarose (Upstate Biotechnology, Inc., Lake
Placid, NY, USA) and immunoprecipitated with antiHIF1 $\alpha$ or anti-GPER antibody or nonspecific IgG. Pellets were washed, eluted with a buffer consisting of $1 \%$ SDS and $0.1 \mathrm{~mol} / \mathrm{L} \mathrm{NaHCO}_{3}$, and digested with proteinase K. DNA was obtained by phenol/chloroform extractions and precipitated with ethanol. The yield of target region DNA in each sample after ChIP was analyzed by real-time PCR. The primer for the $-1,216$ to -883 region of the human VEGF promoter containing the HRE site is 5'-CACAGACCTTCACAGCCATC-3' (forward hHRE) and 5'-CCCAGCGTAGACAGTTGAGT-3' (reverse hHRE). Data were normalized to the input for the immunoprecipitation. For knockdown experiments CAFs were previously transfected in serumfree medium for $24 \mathrm{~h}$ with shHIF-1 $\alpha$ or shGPER and the respective control shRNA (as described above) and then treated for $1 \mathrm{~h}$ with $100 \mu \mathrm{M} \mathrm{CoCl}_{2}$.

\section{Migration assay}

Migration assays were performed with CAFs in triplicate using Boyden chambers (Costar Transwell, $8 \mathrm{~mm}$ polycarbonate membrane, Sigma Aldrich Srl). CAFs were transfected with shRNA constructs directed against HIF-1 $1 \alpha$, GPER or with an unrelated control shRNA construct in regular growth medium. After $24 \mathrm{~h}$, cells were exposed to low oxygen tension $\left(2 \% \mathrm{O}_{2}\right)$ or normoxia $\left(20 \% \mathrm{O}_{2}\right)$ for $6 \mathrm{~h}$ in medium without serum. Then, cells were maintained for $24 \mathrm{~h}$ in normoxic conditions $\left(20 \% \mathrm{O}_{2}\right)$ in medium without serum. This experimental condition has been designed in order to reproduce the unbalanced oxygenation occurring within solid tumors, where the irregular blood flow is responsible for hypoxia and reoxygenation phases [27]. CAFs were, therefore, trypsinized and seeded in the upper chambers. CTGF $(100 \mathrm{ng} / \mathrm{mL})$ was added to the medium without serum in the bottom wells where applicable. Six hours after seeding, cells on the bottom side of the membrane were fixed and counted.

\section{Conditioned medium}

CAFs were cultured in regular growth medium to $80 \%$ confluence. Then, cells were washed twice with PBS and transfected in serum-free RPMI 1640 (Invitrogen) with shHIF-1 $\alpha$, shGPER or control shRNA using Fugene 6 reagent as recommended by the manufacturer (Roche Diagnostics) for $24 \mathrm{~h}$. Subsequently, cells were incubated under normoxic or hypoxic $\left(2 \% \mathrm{O}_{2}\right)$ conditions for $12 \mathrm{~h}$. Thereafter, the culture supernatant was collected, centrifuged at $16,000 \mathrm{~g}$ for five minutes to remove cell debris and used as conditioned medium in HUVECs.

\section{Protein precipitation with Trichloroacetic acid (TCA)}

Conditioned medium from CAFs (see above) was collected, centrifuged at 16,000 $\mathrm{g}$ for five minutes to remove cell debris and $10 \mu \mathrm{g} / \mathrm{mL}$ BSA (final concentration) was 
added as a control for precipitation efficiency. TCA (100\% solution) was added to a final concentration of $20 \%$ to conditioned media. After a 20-minute incubation on ice, the samples were centrifuged at $31,000 \mathrm{~g}$ for 20 minutes $\left(4^{\circ} \mathrm{C}\right)$. Pellets were washed with cold acetone, centrifuged at $31,000 \mathrm{~g}$ for 30 minutes $\left(4^{\circ} \mathrm{C}\right)$, air dried and resuspended in protein lysis buffer (described above). Protein concentrations were estimated using the Bradford Method and immunoblot analysis was performed as described above, using $100 \mu \mathrm{g}$ protein/lane.

\section{Tube formation assay}

The day before the experiment, confluent HUVECs were starved overnight at $37^{\circ} \mathrm{C}$ in serum free medium (EBM, Lonza, Milan, Italy). Growth factor-reduced Matrigel ${ }^{\circledR}$ (Cultrex, Trevigen, Inc., Helgerman Court, Gaithersburg, USA) was thawed overnight at $4^{\circ} \mathrm{C}$ on ice, plated on the bottom of pre-chilled 96-well plates and left at $37^{\circ} \mathrm{C}$ for $1 \mathrm{~h}$ for gelification. Starved HUVECs were collected by enzymatic detachment (0.25\% trypsin-EDTA solution, Invitrogen), counted and resuspended in conditioned medium from CAFs. Then, 10,000 cells/well were seeded on Matrigel ${ }^{\circledR}$ and incubated at $37^{\circ} \mathrm{C}$. Tube formation was observed starting from $2 \mathrm{~h}$ after cell seeding and quantified by using the software NIH ImageJ (National Institutes of Health (NIH), Rockville Pike, Bethesda, Maryland, USA).

\section{Statistical analysis}

Statistical analysis was performed using ANOVA followed by Newman-Keuls' testing to determine differences in means. $P<0.05$ was considered as statistically significant.

\section{Results}

\section{Hypoxia induces HIF- $1 \alpha$ and GPER expression in CAFs}

In order to provide further insight into the response to hypoxia in main components of the tumor microenvironment like CAFs, we began our study showing that hypoxia induces the mRNA expression of both $H I F-1 \alpha$ and its target gene GPER, as ascertained by real time PCR (Figure 1) and semi-quantitative PCR (data not shown). In particular, CAFs were treated from $1 \mathrm{~h}$ to $24 \mathrm{~h}$ with the hypoxia mimetic agent $\mathrm{CoCl}_{2}(100 \mu \mathrm{M})$ (Figure 1a) or cultured in the presence of low oxygen tension $\left(2 \% \mathrm{O}_{2}\right)$ (Figure $\left.1 \mathrm{~b}\right)$. The induction of $H I F-1 \alpha$ and GPER mRNA expression was paralleled by increased protein levels of these factors in CAFs treated from $1 \mathrm{~h}$ to $24 \mathrm{~h}$ with $100 \mu \mathrm{M} \mathrm{CoCl}_{2}$ (Figure 1c) or exposed to a low oxygen tension $\left(2 \% \mathrm{O}_{2}\right)$ (Figure 1d). Next, silencing HIF-1 $\alpha$ expression, the induction of GPER by $\mathrm{CoCl}_{2}$ was abrogated (Figure 1e, Additional file 1a), indicating that HIF- $1 \alpha$ is required for the transcription of GPER in CAFs exposed to hypoxic conditions. In order to assess the transduction signaling involved in the aforementioned responses, we determined the rapid ERK1/2 phosphorylation (from 15 minutes up to 60 minutes) following the treatment with $100 \mu \mathrm{M} \mathrm{CoCl}_{2}$ (Figure 2a). Accordingly, we observed similar effects on ERK1/2 activation culturing CAFs in the presence of low oxygen tension ( $2 \% \mathrm{O}_{2}$ for 30 minutes) (Figure $2 \mathrm{~b}$ ). Next, the treatment with $100 \mu \mathrm{M} \mathrm{CoCl}$ for 30 minutes in the presence of $300 \mu \mathrm{M}$ of the ROS scavenger NAC did not induce the ERK1/2 phosphorylation (Figure 2c). Moreover, the increase of HIF- $1 \alpha$ and GPER observed treating CAFs for $3 \mathrm{~h}$ with $100 \mu \mathrm{M} \mathrm{CoCl}$ was no longer evident in the presence of $300 \mu \mathrm{M}$ NAC and $10 \mu \mathrm{M}$ of the MEK inhibitor PD (Figure 2d). On the basis of these results, it could be argued that hypoxia-induced ROS may trigger the ERK1/2 phosphorylation, which is involved in the up-regulation of both HIF- $1 \alpha$ and GPER expression.

\section{HIF-1 $\alpha$ and GPER are involved in the expression of VEGF induced by hypoxia}

Considering the ability of a low oxygen environment to trigger the production of pro-angiogenic factors in solid tumors, we aimed to evaluate whether hypoxia may promote the expression of an important HIF-1 $\alpha$ target gene like VEGF. As shown in Figure 3a, the treatment with $\mathrm{CoCl}_{2}$ induced the mRNA expression of VEGF in a time-dependent manner in both CAFs and SkBr3 breast cancer cells. Similar results were obtained in a completely different model system, such as HL-1 cardiomyocytes (Additional file 2). Next, $\mathrm{CoCl}_{2}$ and a low oxygen tension $\left(2 \% \mathrm{O}_{2}\right)$ activated a VEGF promoter reporter gene which was transfected in CAFs and SkBr3 cells (Figure 3b, c). Notably, the aforementioned transcriptional response to hypoxia was abrogated knocking-down HIF-1 $\alpha$ and GPER expression (Figure 3d, e and Additional file 1c, d). $\mathrm{CoCl}_{2}$ and a low oxygen tension $\left(2 \% \mathrm{O}_{2}\right)$ promoted also VEGF protein expression in CAFs, as evidenced by immunofluorescence experiments (Figure 4). The induction of VEGF protein levels was abolished, silencing HIF-1 $\alpha$ and GPER expression (Figure 5 and Additional file 1a, b), further highlighting their involvement in the regulation of VEGF by hypoxia. Analogously, the up-regulation of VEGF protein expression upon exposure to hypoxia in $\mathrm{SkBr} 3$ (Figure 6a) and HL-1 cells (Figure 7a) was no longer evident, knocking down the expression of GPER (Figures 6b and $7 \mathrm{~b}$ and Additional file 1e) and HIF-1 $\alpha$ (data not shown). Taken together, these results suggest that HIF-1 $\alpha$ and GPER are involved in the regulation of VEGF expression induced by hypoxia.

\section{HIF- $1 \alpha$ and GPER are both recruited to the VEGF promoter and involved in VEGF-mediated tube formation induced by hypoxia}

As HIF- $1 \alpha$ and GPER are required for the hypoxiainduced VEGF expression, we next determined by ChIP assay that HIF-1 $\alpha$ (Figure $8 \mathrm{a}$ ) and GPER (Figure $8 \mathrm{~b}$ ) are 


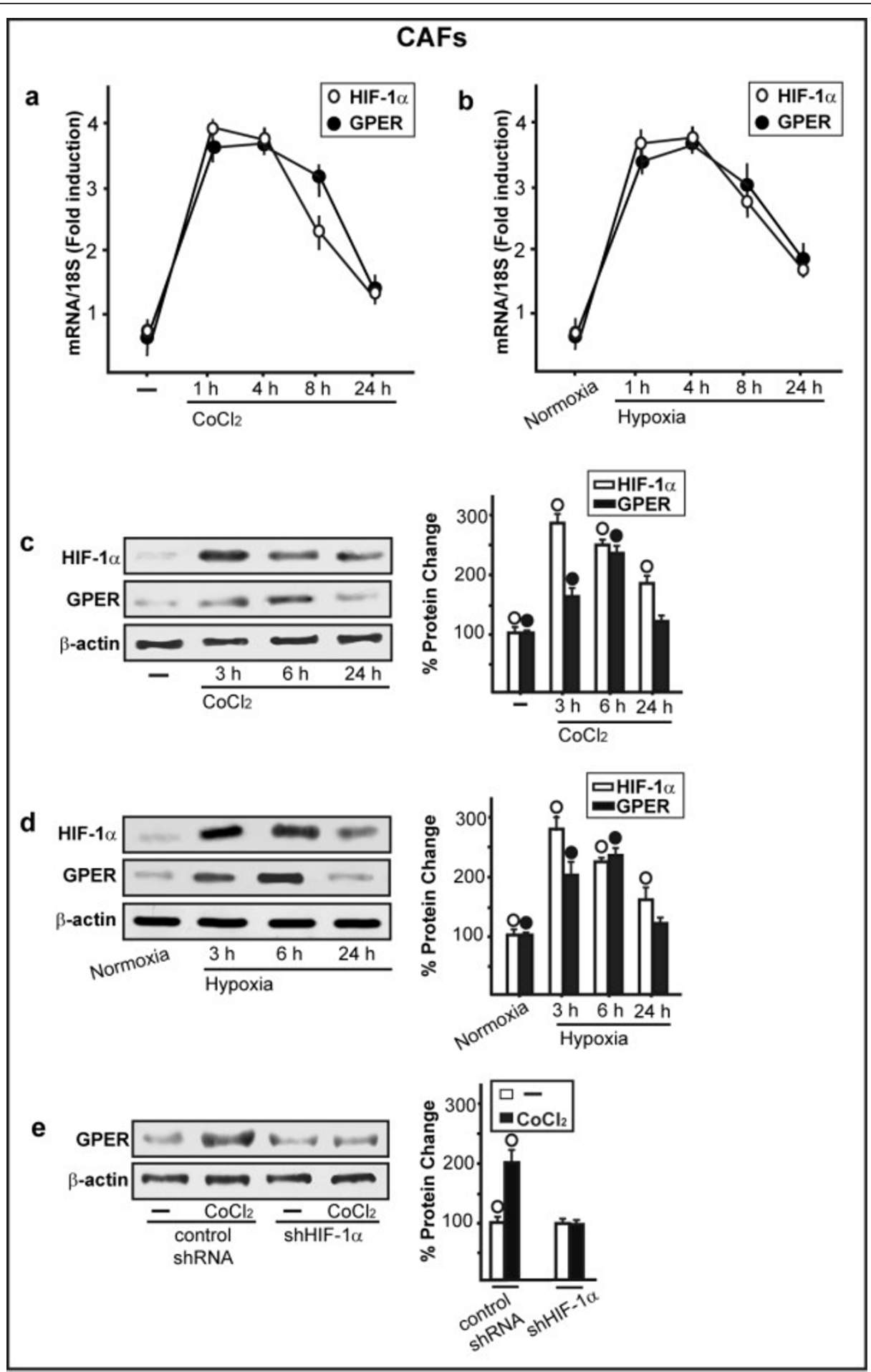

Figure 1 Hypoxia induces the expression of HIF-1 $\alpha$ and GPER in CAFs. (a-d) The exposure to $100 \mu \mathrm{M} \mathrm{CoCl} 2$ (a, c) or low oxygen tension $\left(2 \% \mathrm{O}_{2}\right.$ for $\left.3 \mathrm{~h}\right)(\mathrm{b}, \mathrm{d})$ up-regulate the mRNA $(\mathrm{a}, \mathrm{b})$ and protein $(c, d)$ expression of HIF- $1 \alpha$ and GPER as evaluated by real-time PCR and immunoblotting, respectively. In RNA experiments, values are normalized to the 185 expression and shown as fold changes of mRNA expression induced by $\mathrm{CoCl}_{2}$ compared to cells treated with vehicle. (e) The up-regulation of GPER observed treating CAFs for $6 \mathrm{~h}$ with $100 \mu \mathrm{M} \mathrm{CoCl}$ is abrogated by silencing HIF-1 $\alpha$. Each data point represents the mean \pm SD of three independent experiments. Side panel shows densitometric analysis of the blots normalized to $\beta$-actin. (०), (•) $P<0.05$ for cells receiving vehicle (-) or cells cultured under normoxia versus $\mathrm{CoCl}_{2}$ treatment or cells cultured under hypoxia. 


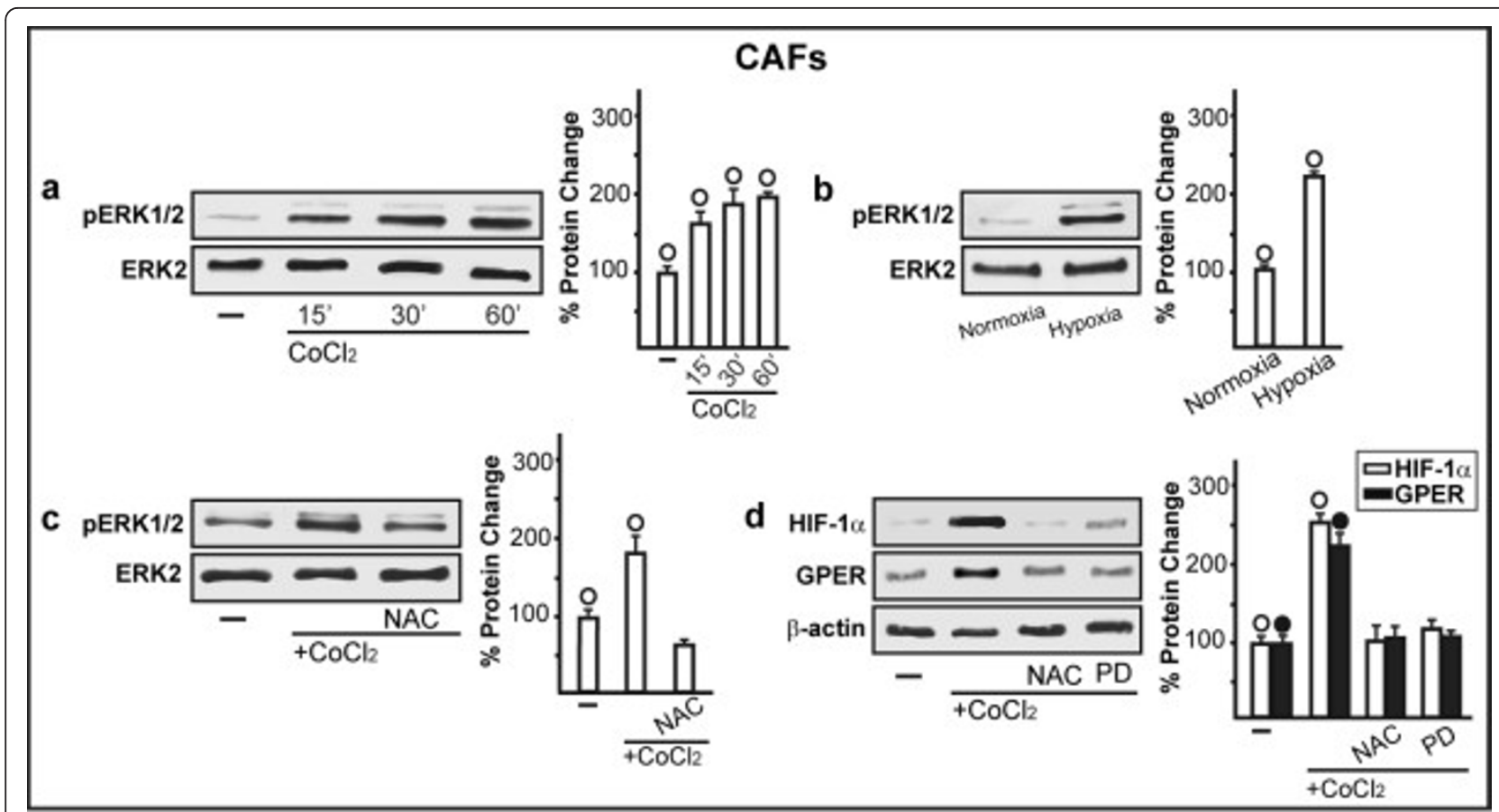

Figure 2 Hypoxia stimulates the expression of HIF- $1 \alpha$ and GPER through ERK1/2 activation in CAFs. The treatment with $100 \mu \mathrm{M} \mathrm{CoCl} 2$ (a) or the exposure to low oxygen tension ( $2 \% \mathrm{O}_{2}$ for 30 minutes) (b) induce ERK1/2 phosphorylation, which is prevented by using $300 \mu \mathrm{M}$ of the free radical scavenger NAC (c). (d) Immunoblots of HIF-1 $\alpha$ and GPER from CAFs treated for $3 \mathrm{~h}$ with vehicle (-) or $100 \mu \mathrm{M} \mathrm{CoCl} 2$ alone and in combination with $300 \mu \mathrm{M}$ NAC or $10 \mu \mathrm{M}$ ERK1/2 inhibitor PD. Results shown are representative of three independent experiments. Side panels show densitometric analysis of the blots normalized to ERK/2 or $\beta$-actin. (०), $(\bullet) P<0.05$ for cells receiving vehicle (-) or cultured under normoxia vs cells treated with $\mathrm{CoCl}_{2}$ or cells cultured under hypoxia.

both recruited to the HRE site located within the VEGF promoter sequence in CAFs exposed to $\mathrm{CoCl}_{2}$ for $1 \mathrm{~h}$. Interestingly, GPER was required for the recruitment of HIF-1 $\alpha$ to the promoter of VEGF, as evidenced knocking-down the expression of GPER (Figure 8c). In parallel, the silencing of HIF- $1 \alpha$ abolished the recruitment of GPER to the HRE site within the VEGF promoter sequence (Figure $8 \mathrm{~d}$ ). Altogether, these findings suggest that a functional interplay between HIF- $1 \alpha$ and GPER leads to the hypoxia-induced transcription of VEGF.

On the basis of these data, we then examined whether conditioned medium from hypoxia-stimulated CAFs could promote in HUVECs the formation of tubule-like structures that represent a useful model system for the evaluation of the neoangiogenesis process [28]. In particular, HUVECs were cultured on GFR-Matrigel ${ }^{\circledR}$-coated plates which prevent the formation of capillary-like structures, as previously reported [29]. Notably, HUVECs cultured in normoxic medium from CAFs did not assemble into cordlike structures, while HUVECs grown in medium from CAFs maintained in hypoxic conditions $\left(2 \% \mathrm{O}_{2}\right.$ for $\left.12 \mathrm{~h}\right)$ displayed a complex ramified network of tubules (Figure 9a). Moreover, in HUVECs cultured with hypoxic medium $\left(2 \% \mathrm{O}_{2}\right.$ for $\left.12 \mathrm{~h}\right)$ collected from CAFs, which were previously transfected with a shHIF- $1 \alpha$ or shGPER, tube formation was no longer observed (Figure 9b, c). The addition of $10 \mathrm{ng} / \mathrm{mL}$ VEGF to the hypoxic medium from GPER-silenced CAFs restored the ability to form tubule structures in HUVECs (Figure 9c). The aforementioned findings were quantified and recapitulated in Additional file 3. Next, we determined that the up-regulation of VEGF protein levels in hypoxic medium from CAFs is no longer evident, knocking down HIF-1 $\alpha$ and GPER expression (Additional file 4). Hence, these results clearly suggest that VEGF may be considered as a target of the HIF-1 $\alpha$ / GPER transduction signaling.

\section{HIF-1 $\alpha$ and GPER are involved in hypoxia-induced} expression of CTGF and migration of CAFs

In order to further corroborate the stimulatory role exerted by HIF-1 $\alpha /$ GPER signaling in hypoxic conditions, we turned to a different model system. $\mathrm{CoCl}_{2}$ and low oxygen tension $\left(2 \% \mathrm{O}_{2}\right)$ induced CTGF up-regulation at both mRNA (Figure 10a) and protein level (Figure 10b, c) in CAFs. Silencing HIF- $1 \alpha$ as well as knocking down GPER expression, the up-regulation of CTGF upon $\mathrm{CoCl}_{2}$ was abolished (Figure 10d, e). As a biological counterpart, the migration of CAFs cultured under low oxygen tension $\left(2 \% \mathrm{O}_{2}\right)$ was prevented, silencing HIF- $1 \alpha$ and GPER expression and rescued, adding CTGF (Figure 10f). 

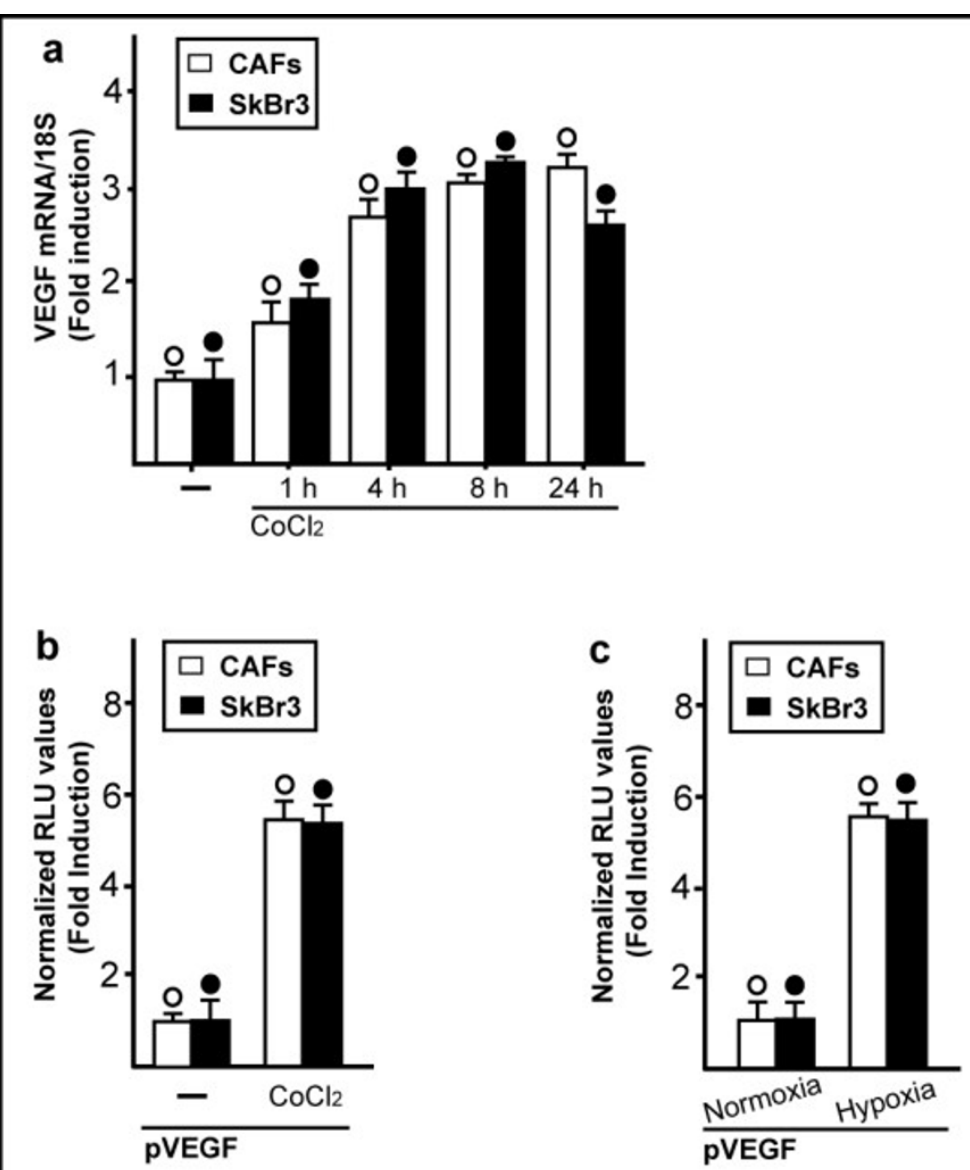

\section{SkBr3}
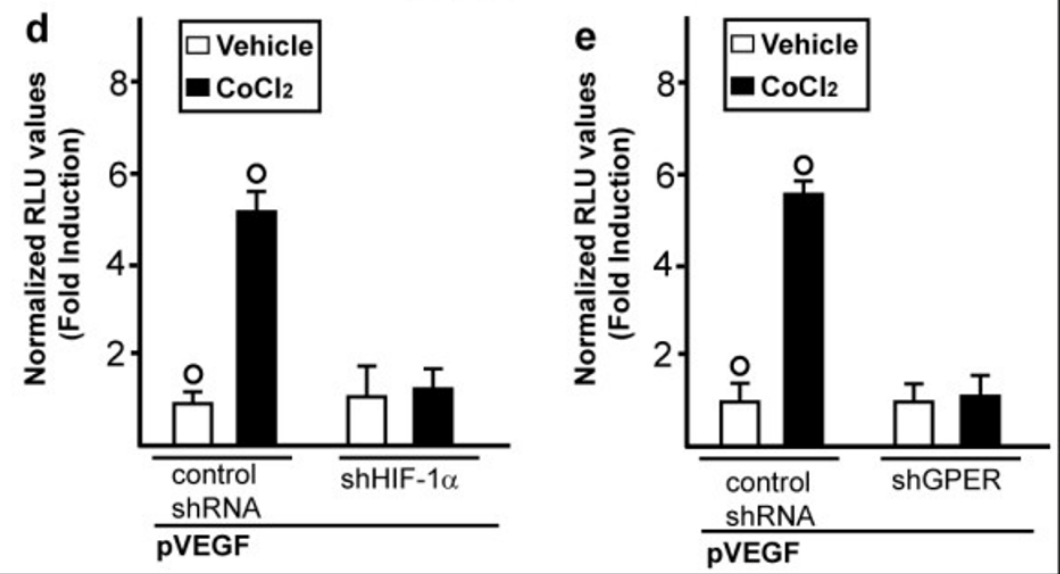

Figure 3 HIF- $1 \alpha$ and GPER are involved in the hypoxia-induced transcriptional activation of VEGF. (a) The mRNA expression of VEGF is up-regulated in CAFs and $\mathrm{SkBr} 3$ cells treated with $100 \mu \mathrm{M} \mathrm{CoCl}$, as evaluated by real-time PCR. Values are normalized to the $18 \mathrm{~S}$ expression and shown as fold changes of mRNA expression induced by $\mathrm{CoCl}_{2}$ compared to cells treated with vehicle (-). Columns, mean of three independent experiments; bars, SD. (b) The VEGF promoter plasmid (pVEGF) is transactivated in CAFs and SkBr3 cells treated with $100 \mu \mathrm{M} \mathrm{CoCl} 2$ for $12 \mathrm{~h}$ (b) or exposed to low oxygen tension $\left(2 \% \mathrm{O}_{2}\right)$ for $12 \mathrm{~h}$ (c). The transactivation of the VEGF promoter observed in $\mathrm{SkBr} 3$ cells treated for $12 \mathrm{~h}$ with $100 \mu \mathrm{M} \mathrm{CoCl} 2$ is abrogated by silencing HIF-1 $\alpha$ (d) or GPER expression (e). The luciferase activities were normalized to the internal transfection control and values of cells receiving vehicle or cultured under normoxia were set as one-fold induction upon which the activities induced by $\mathrm{CoCl}_{2}$ treatment or hypoxia were calculated. Each data point represents the mean \pm SD of three independent experiments performed in triplicate. (०), (•) $P<0.05$ for cells receiving vehicle $(-)$ or cultured under normoxia vs cells treated with $\mathrm{CoCl}_{2}$ or cells cultured under hypoxia. 


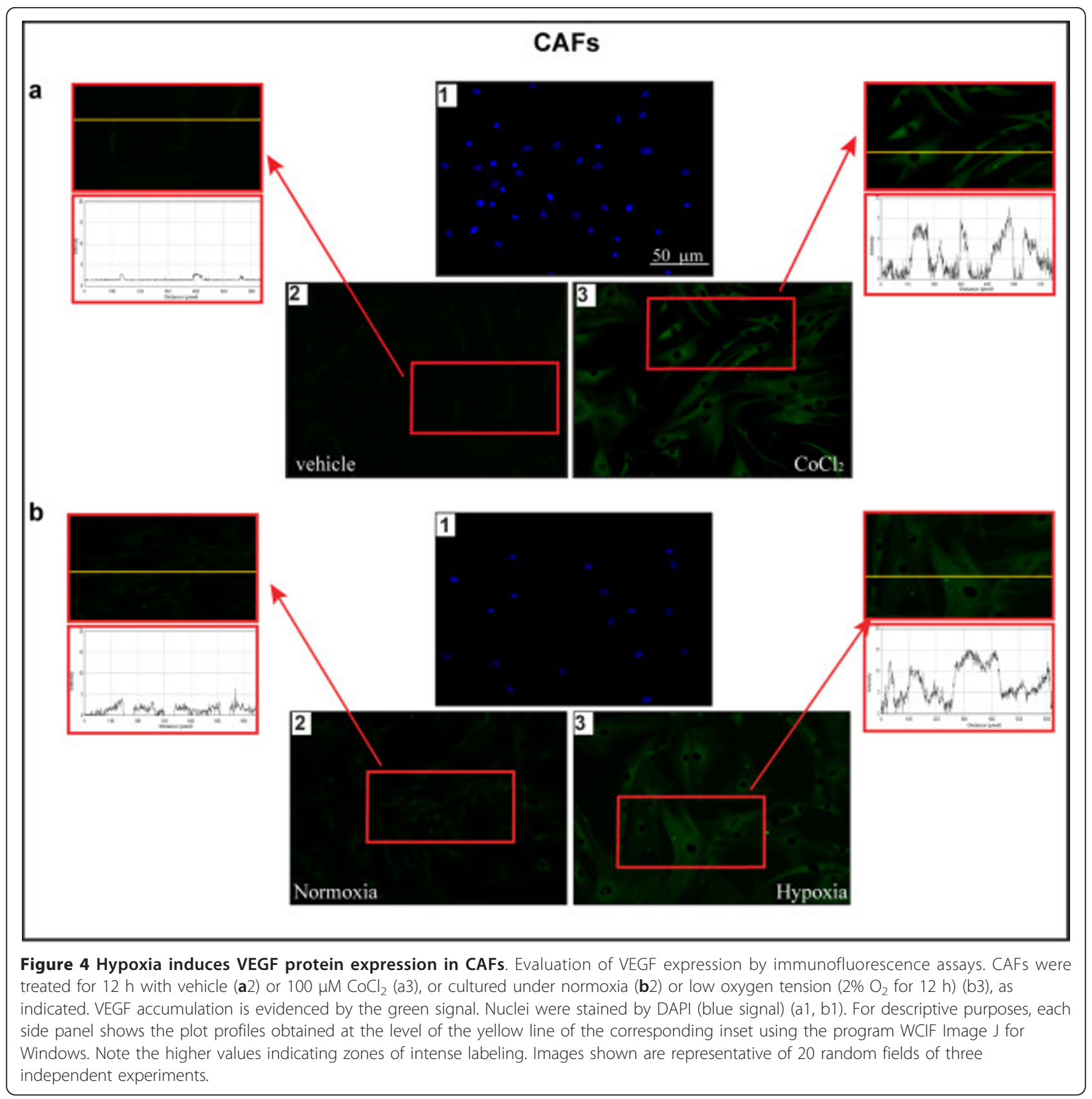

Collectively, our data may suggest that HIF-1 $\alpha /$ GPER signaling mediates different biological outcomes in CAFs exposed to hypoxia.

\section{Discussion}

In the present study, we provide novel evidence regarding the regulation of VEGF, which plays a fundamental role in mediating hypoxia-induced tumor angiogenesis [30,31]. In particular, our results demonstrate that a low oxygen tension stimulates through the ERK1/2 transduction pathway the HIF- $1 \alpha$ dependent expression of GPER, which contributes to the regulation of VEGF in both CAFs and breast cancer cells. Moreover, we show that following hypoxic conditions, HIF- $1 \alpha$ and GPER are both recruited to the HRE site located within the VEGF promoter region and cooperatively act as a functional complex for the transcription of VEGF. As a biological counterpart, we evidence that HIF- $1 \alpha$ and GPER mediate endothelial tube formation in HUVECs cultured in medium from CAFs which were previously exposed to hypoxia. Further corroborating these findings, we demonstrate that the cross-talk between HIF- $1 \alpha$ and GPER regulates the expression of the migratory factor CTGF, which has been acknowledged as a target gene of both HIF-1 $\alpha$ and GPER $[19,20]$. 


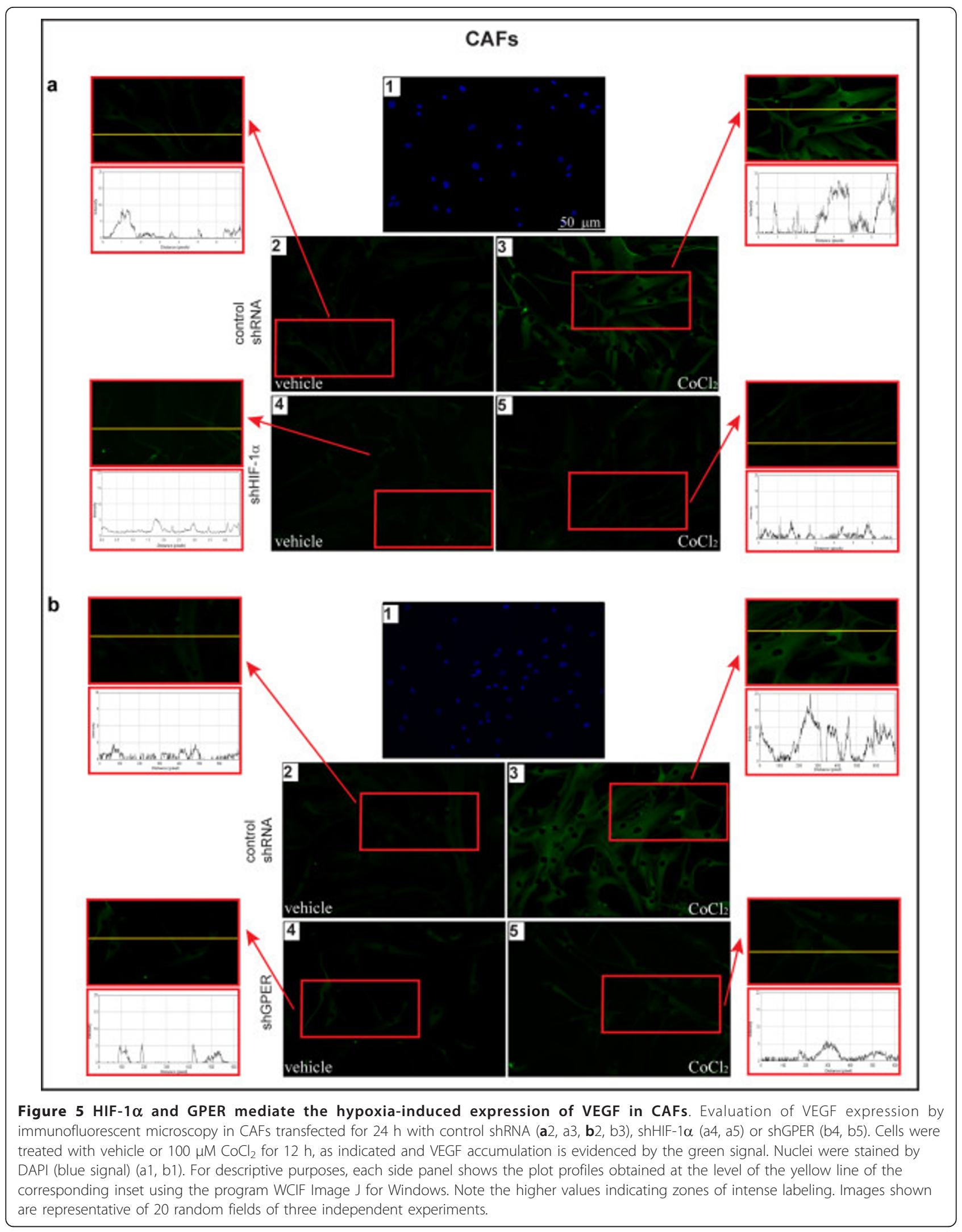




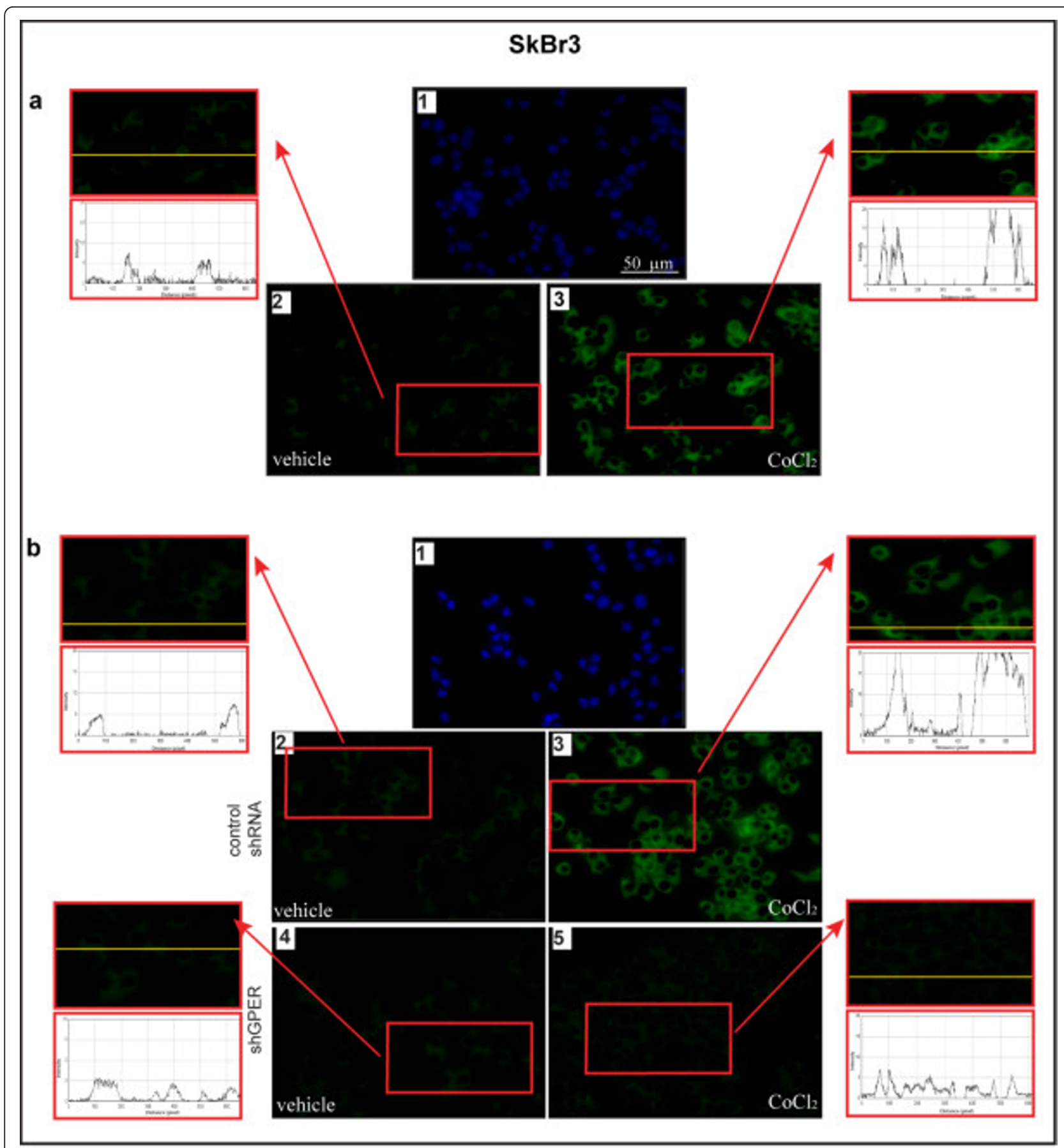

Figure 6 GPER is involved in VEGF expression by hypoxia in SkBr3 breast cancer cells. (a) SkBr3 cells were treated for $12 \mathrm{~h}$ with vehicle (a2) or $100 \mu \mathrm{M} \mathrm{CoCl}_{2}$ (a3), as indicated. VEGF accumulation is evidenced by the green signal. (b) SkBr3 cells were transfected for $24 \mathrm{~h}$ with control shRNA (b2, b3) or shGPER (b4, b5) and treated with vehicle (b2, b4) or $100 \mu \mathrm{M} \mathrm{CoCl}$ (b3, b5) for 12 h, as indicated. VEGF accumulation was evidenced by the green signal. Nuclei were stained by DAPI (blue signal) (a1, b1). For descriptive purposes, each side panel shows the plot profiles obtained at the level of the yellow line of the corresponding inset using the program WCIF Image J for Windows. Note the higher values indicating zones of intense labeling. Images shown are representative of 20 random fields of three independent experiments.

HIF-1 is a master regulator of cellular adaptation to oxygen deprivation and acts as a survival factor in hypoxic tumor environment, mainly activating the transcription of genes involved in glycolytic metabolism, oxygen consumption, cell migration and invasion $[15,32]$. Besides, hypoxia stimulates through HIF-1 the expression of anti-apoptotic, proliferative and angiogenic factors that drastically change the biological properties 


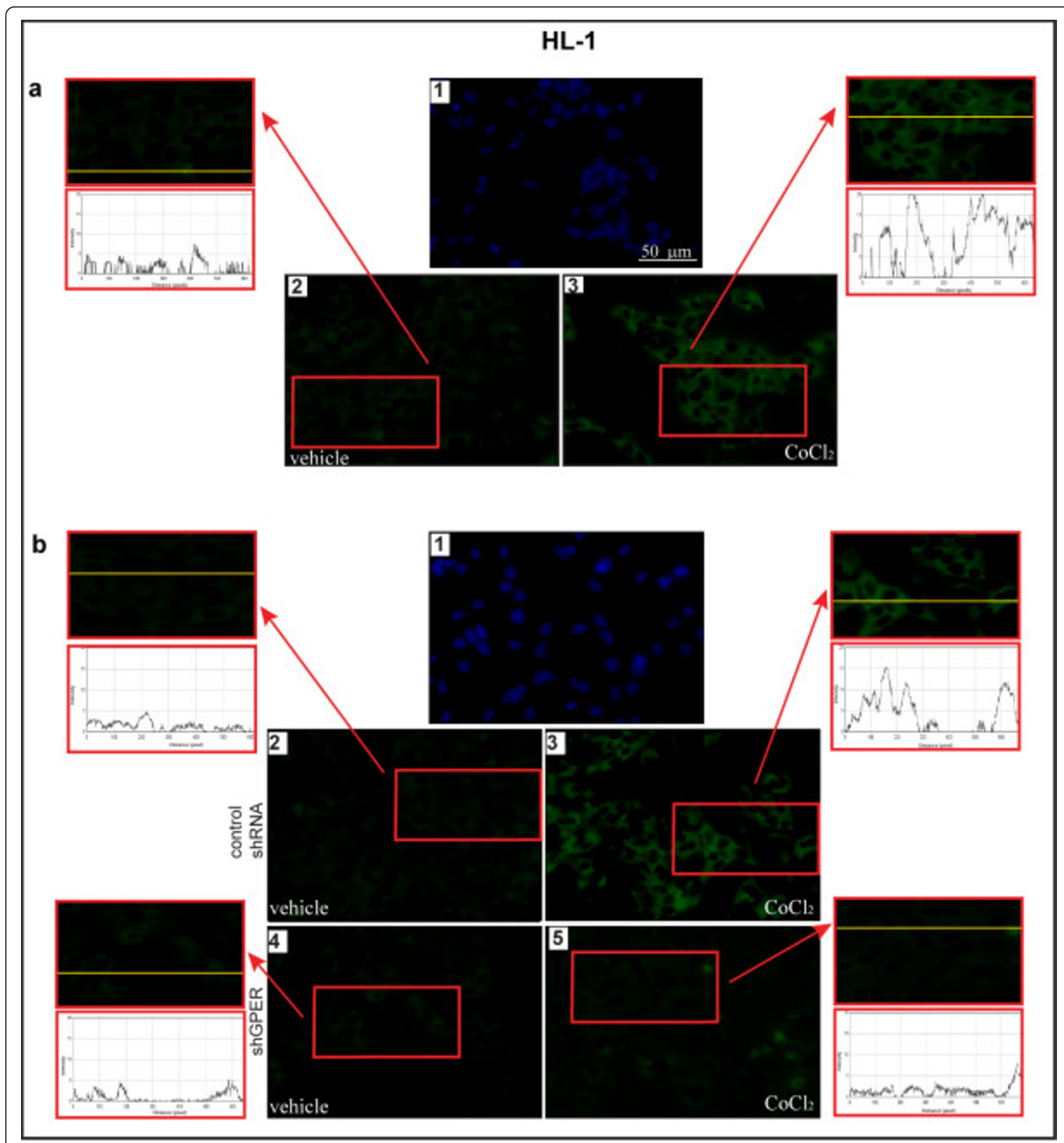

Figure 7 GPER is involved in VEGF expression by hypoxia in HL-1 murine cardiomyocytes. (a) HL-1 cells were treated for $12 \mathrm{~h}$ with vehicle (a2) or $100 \mu \mathrm{M} \mathrm{CoCl}_{2}$ (a3), as indicated. VEGF accumulation is evidenced by the green signal. (b) $\mathrm{HL}-1$ cells were transfected for $24 \mathrm{~h}$ with control shRNA $(b 2, b 3)$ or shGPER $(b 4, b 5)$ and treated with vehicle $(b 2, b 4)$ or $100 \mu \mathrm{M} \mathrm{CoCl}_{2}(b 3, b 5)$ for $12 \mathrm{~h}$, as indicated. VEGF accumulation is evidenced by the green signal. Nuclei were stained by DAPI (blue signal) (a1, b1). For descriptive purposes, each side panel shows the plot profiles obtained at the level of the yellow line of the corresponding inset using the program WCIF Image J for Windows. Note the higher values indicating zones of intense labeling. Images shown are representative of 20 random fields of three independent experiments.

of tumor cells towards malignant features [12]. In this context, we have recently demonstrated that GPER may be included among the HIF-1 target genes as the upregulation of GPER induced by hypoxia occurs through the recruitment of HIF- $1 \alpha$ to the HRE site located within the GPER promoter sequence in breast cancer cells and cardiomyocytes [19]. In particular, GPERmediated the antiapoptotic effects exerted by estrogens 


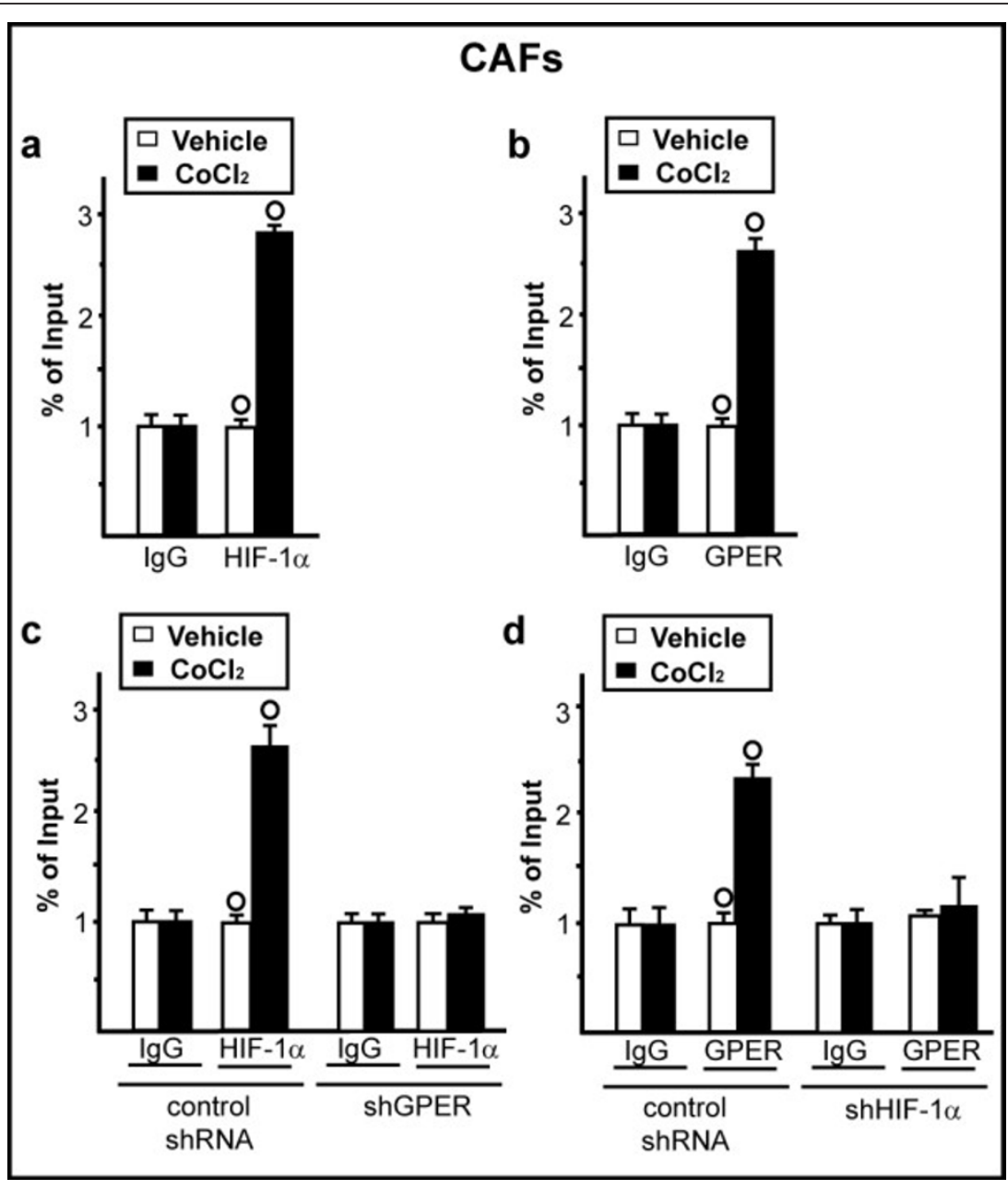

Figure 8 HIF- $1 \alpha$ and GPER are recruited to the VEGF promoter sequence. CAFs treated for $1 \mathrm{~h}$ with $100 \mu \mathrm{M} \mathrm{CoCl} \mathrm{L}_{2}$ were submitted to the chromatin immunoprecipitation procedure using anti-HIF-1 $\alpha$ (a) or anti-GPER (b) antibodies. For knockdown experiments, CAFs were transfected with control shRNA and shGPER (c) or with control shRNA and shHIF-1 $\alpha$ (d), treated for $1 \mathrm{~h}$ with $100 \mu \mathrm{M} \mathrm{CoCl}$ and then submitted to the chromatin immunoprecipitation procedure using anti-HIF-1 $\alpha$ (c) or anti-GPER (d) antibodies. The amplified sequences were evaluated by real-time PCR. Each data point represents the mean $\pm \mathrm{SD}$ of three independent experiments. ( $(\circ) P<0.05$ for cells receiving vehicle vs $\mathrm{CoCl}_{2}$ treatment.

in hypoxic conditions, suggesting that this receptor may contribute to the adaptation of cancer cells to a low oxygen environment [19].

GPER may be considered as a predictor of cancer malignancy and aggressiveness considering that its expression has been associated with negative clinical features and poor survival rates in diverse types of tumors [33-35]. Therefore, huge efforts are currently underway to unravel the mechanisms that rule its regulation and function. Indeed, the development and characterization of drugs that target key players of cancer progression like GPCRs [36,37], and particularly GPER, are currently innovative topics under investigation [38,39].

In this context, estrogenic GPER signaling has been shown to trigger relevant biological effects like proliferation and migration in diverse cancer cells and in CAFs derived from breast tumors [40-43]. Notably, GPER exhibited the peculiar property to act in CAFs as a transcriptional regulator together with the epidermal growth factor receptor (EGFR), hence leading to the up-regulation of Cyclin D, which has been largely involved in cell proliferation [23]. Increasing evidence has suggested that CAFs may drive cancer phenotype mainly through a paracrine action exerted by the production of various growth factors and chemokines secreted in the tumor microenvironment $[3,4,44,45]$. Indeed, the stromal contribution to the development of a wide variety of tumors has been supported by animal models of cancer pathogenesis $[46,47]$ and extensive clinical studies [48]. In this vein, it has been shown that malignant cells recruit into the tumor mass diverse stromal components like CAFs, inflammatory and vascular cells that actively cooperate towards cancer progression [46,49-51]. In particular, CAFs elicit in breast carcinomas relevant biological activities, 


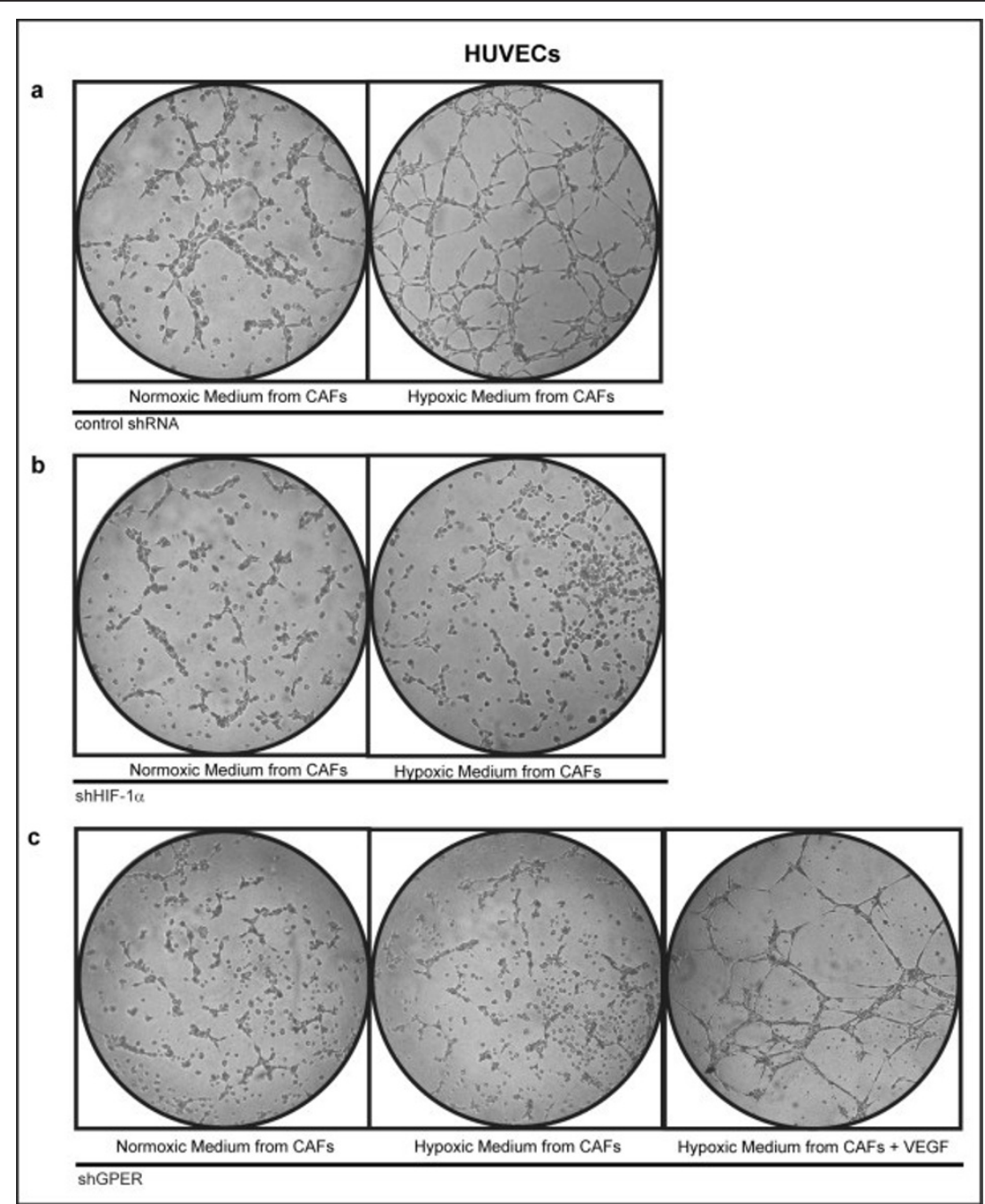

Figure 9 Involvement of HIF-1 $\alpha$ and GPER in hypoxia-induced tube formation. Tube formation was evaluated in HUVECS cultured for $2 \mathrm{~h}$ in medium collected from CAFs which were cultured under normoxia or hypoxia ( $2 \% \mathrm{O}_{2}$ for $12 \mathrm{~h}$ ). To this end, CAFs were transfected with control shRNA (a), shHIF-1 $\alpha$ (b) or shGPER (c) and exposed to hypoxia, as indicated. Tube formation is rescued in HUVECs treated with $10 \mathrm{ng} / \mathrm{mL}$ VEGF and cultured in medium from CAFs transfected with shGPER and cultured under hypoxia $\left(2 \% \mathrm{O}_{2}\right.$ for $12 \mathrm{~h}$ ). Data are representative of three independent experiments performed in triplicate.

including the stimulation of new blood vessels formation, which closely correlates with cancer growth, metastasis and poor prognosis [52,53]. In this context, our present data add a further mechanism through which the tumor microenvironment may promote angiogenesis, as the HIF$1 \alpha /$ GPER signaling was shown to mediate the up-regulation of VEGF expression in CAFs cultured in hypoxic conditions. Considering that VEGF is one of the most important factors mediating the complex process of angiogenesis [54], its action has been widely involved in the development of many types of tumors, including breast cancer [55]. Accordingly, it has been shown that the ectopic expression of VEGF in MCF-7 breast cancer cells may promote tumor growth in vivo [56], whereas the blockade of VEGF has been associated with the growth arrest of breast carcinomas in nude mice $[57,58]$. Thus, given the crucial role exerted by VEGF in tumor development and prognosis, a great deal of interest is currently addressed to a better understanding of its regulation and function. In this regard, VEGF was shown to be regulated by hypoxia mainly through HIF-1 $\alpha$, which may interact with numerous factors to boost VEGF expression $[59,60]$. Further extending the current knowledge on the complex regulation of VEGF, our data suggest that GPER may contribute to the HIF- $1 \alpha$ mediated transcriptional responses in hypoxic tumor microenvironment towards new blood vessel formation. Notably, an increased VEGF production was recently shown to parallel an elevated GPER expression in endometrial cancer patients with low survival rates [61]. These data in combination with our 


\section{CAFs}
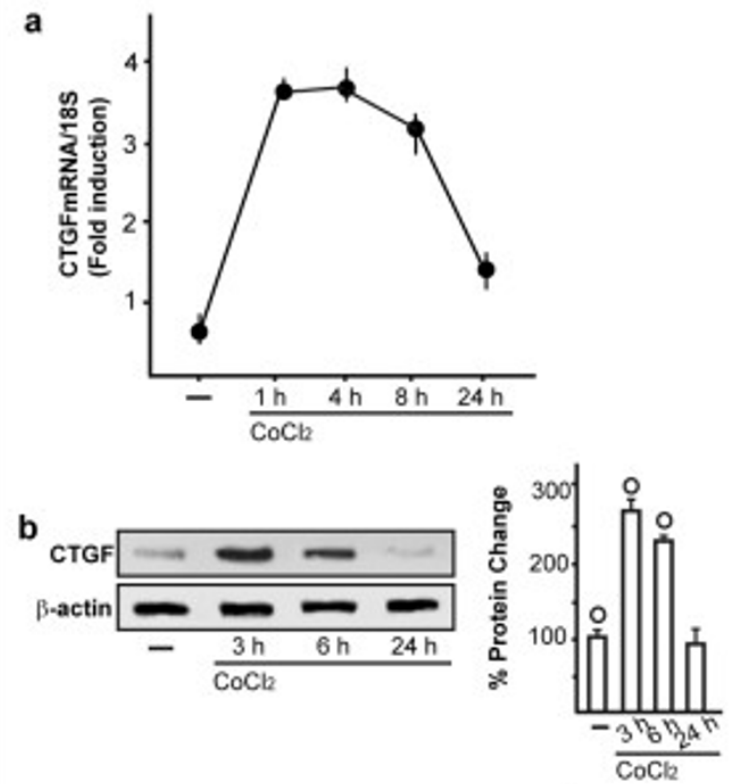

C
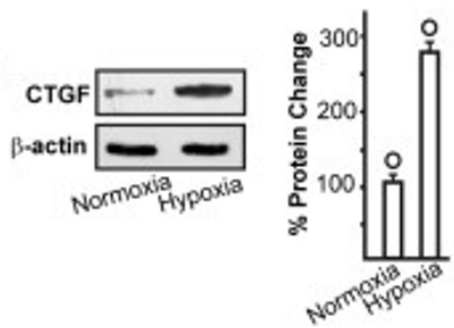

d

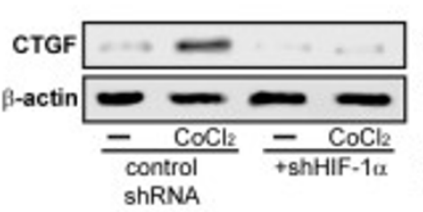

f
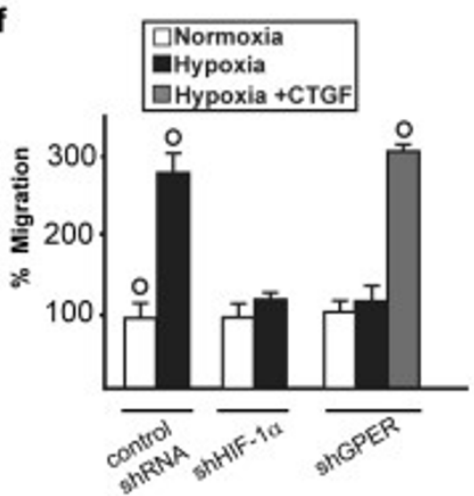

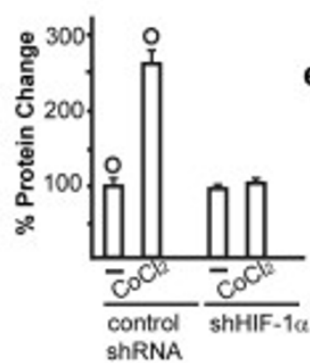

e
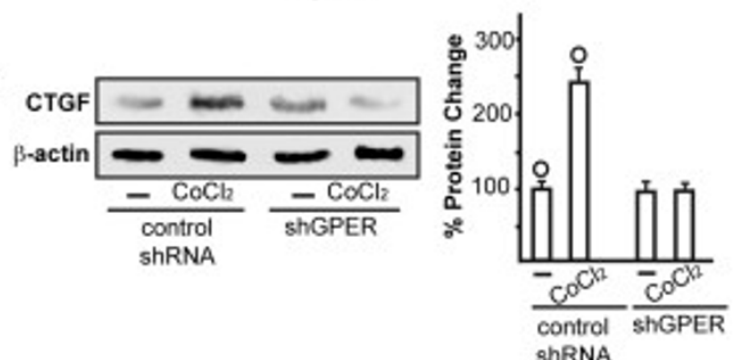

Figure 10 Involvement of HIF-1 $\alpha$ and GPER in hypoxia-induced expression of CTGF and migration of CAFs. (a) The mRNA expression of CTGF is induced after the stimulation of CAFs with $100 \mu \mathrm{M} \mathrm{CoCl}$, as indicated. Values are normalized to the 185 expression and shown as fold changes of mRNA expression induced by $\mathrm{CoCl}_{2}$ compared to cells treated with vehicle. The protein expression of CTGF is induced by $100 \mu \mathrm{M} \mathrm{CoCl}$ (b) or low oxygen tension $\left(2 \% \mathrm{O}_{2}\right.$, for $4 \mathrm{~h}$ ) (c). The up-regulation of CTGF protein expression observed upon $100 \mathrm{\mu M} \mathrm{CoCl}_{2}$ treatment is abrogated silencing HIF-1 $\alpha$ (d) or GPER (e) expression. The migration of CAFs induced by hypoxia $\left(2 \% \mathrm{O}_{2}\right.$, for $\left.6 \mathrm{~h}\right)$ is prevented knocking down HIF-1 $\alpha$ and GPER expression. Cell migration is rescued in CAFs transfected with shGPER, exposed to hypoxia ( $2 \% \mathrm{O}_{2}$, for $6 \mathrm{~h}$ ) and treated with $100 \mathrm{ng} / \mathrm{ml}$ CTGF (f). Results shown are representative of three independent experiments. Side panels show densitometric analysis of the blots normalized to $\beta$-actin. ( $(0) P$ $<0.05$ for cells receiving vehicle (-) or cells cultured under normoxia versus $\mathrm{CoCl}_{2}$ treatment or cells cultured under hypoxia.

findings may suggest that in estrogen-dependent cancer cells diverse molecular mechanisms could converge on the production of cytokines and growth factors, promoting an enhancement of malignant epithelial growth and invasion through autocrine and/or paracrine pathways. Interestingly, we have determined that the up-regulation of VEGF relied on HIF-1 $\alpha /$ GPER signaling also in HL-1 cardiomyocytes exposed to hypoxia, suggesting that this transduction 
mechanism may be implicated in additional pathophysiological conditions, such as the hypoxic myocardium. In this regard, it should be mentioned that recent studies have suggested a cardioprotective role exerted by GPER in stressful conditions following hypoxia [62]. These data in combination with the results obtained in the present study may indicate that GPER could elicit cardiotropic effects also through its ability to regulate the expression of VEGF, which mainly contributes to adaptive responses following myocardial ischemic injury [63].

As it concerns the signaling cascades activated by hypoxia, we here demonstrate that the ROS-mediated ERK1/2 activation is involved in the up-regulation of HIF$1 \alpha$ and GPER expression upon low oxygen tension. In this regard, it should be mentioned that ROS play a relevant role in the biological responses to re-oxygenation; however, decreased oxygen levels may be sufficient to trigger HIF-1-dependent gene expression through the ROS production [64-66]. In addition, the rapid responses to hypoxia are mediated by multiple transduction pathways activated also upon GPER stimulation $[67,68]$. Further studies are needed to better clarify the functional cross-talk between HIF- $1 \alpha$ and GPER, particularly following both hypoxic and estrogenic stimulations. For instance, estrogens regulate HIF- $1 \alpha$ expression and function in a stressful environment [20], indicating an intricate cooperation between these two main factors mainly involved in tumor progression. Interestingly, in the current investigation, the biological interaction between HIF- $1 \alpha$ and GPER upon hypoxic conditions was corroborated by the up-regulation of an important migratory stimulator and GPER target gene like CTGF. Accordingly, the migration of CAFs induced by hypoxia was abolished, silencing HIF- $1 \alpha$ and GPER expression, hence confirming their contribution to this relevant cell response.

The results obtained in the current study may also disclose a unique ligand-independent action elicited by GPER. This issue could be a further attractive topic which remains to be elucidated in future studies.

Altogether, our findings recapitulate in CAFs exposed to hypoxia the engagement of the HIF-1 $\alpha /$ GPER signaling towards the regulation of pivotal genes involved in angiogenic and metastatic processes. Anyway, further studies are required to better define the role exerted by this transduction pathway in diverse pathophysiological conditions as well as the molecular mechanisms driving the biological responses to hypoxia through the functional interaction between HIF-1 $\alpha$ and GPER.

\section{Conclusions}

Within the tumor microenvironment exposed to hypoxia, CAFs have been involved in the generation of new blood vessels which mainly support cancer progression. Our current data highlight the stimulatory role exerted by the HIF-1 $\alpha$ /GPER signaling in the multistep process of tumor neoangiogenesis fostered by CAFs. Considering the crucial interplay between cancer cells and stroma, the HIF-1 $\alpha$ / GPER transduction pathway may be pointed out as a further biological target towards innovative treatments in breast cancer.

\section{Additional material}

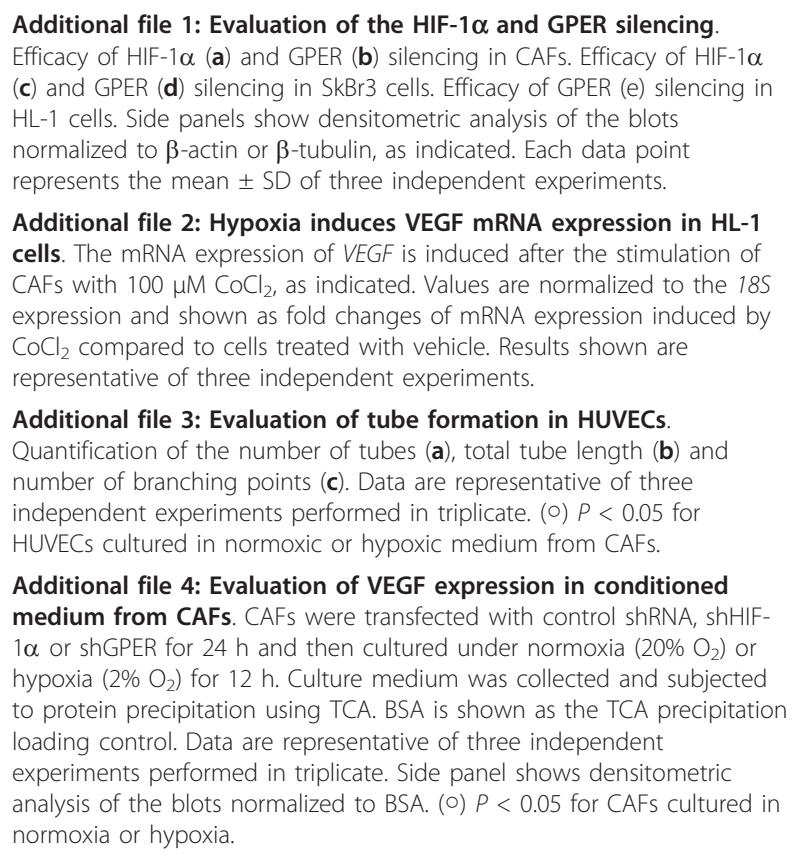

Additional file 4: Evaluation of VEGF expression in conditioned medium from CAFs. CAFs were transfected with control shRNA, shHIF$1 \alpha$ or shGPER for $24 \mathrm{~h}$ and then cultured under normoxia $\left(20 \% \mathrm{O}_{2}\right)$ or hypoxia $\left(2 \% \mathrm{O}_{2}\right)$ for $12 \mathrm{~h}$. Culture medium was collected and subjected to protein precipitation using TCA. BSA is shown as the TCA precipitation loading control. Data are representative of three independent

experiments performed in triplicate. Side panel shows densitometric analysis of the blots normalized to BSA. (०) $P<0.05$ for CAFs cultured in normoxia or hypoxia.

\section{Abbreviations}

CAFs: Carcinoma activated fibroblasts; CTGF: connective tissue growth factor; $\mathrm{CoCl}_{2}$ : cobalt chloride; DAPI: 4',6-Diamidino-2-phenylindole dihydrochloride; EGFR: epidermal growth factor receptor; EGM: endothelial growth medium; ERK: extracellular signal-regulated kinase; FAPa: fibroblast activated protein a; FBS: fetal bovine serum; GPER: G-Protein estrogen receptor; HIF-1: Hypoxia Inducible Factor-1; HREs: hypoxia-responsive elements; HUVECs: human umbilical vein endothelial cells; N-acetyl-L-cysteine; PBS: phosphate-buffered saline; PMSF: phenylmethanesulfonyl fluoride; TCA: trichloroacetic acid; VEGF: vascular endothelial growth factor.

\section{Competing interests}

The authors declare that they have no competing interests.

\section{Authors' contributions}

EMDF designed and performed the experiments, and wrote the paper. RL, MFS and SM performed the experiments. AC designed the experiments and analyzed data. MM designed the experiments, analyzed data and wrote the paper. All authors read and approved the final manuscript for publication.

\section{Acknowledgements}

This work was supported by Associazione Italiana per la Ricerca sul Cancro (biennial fellowship "Isabella Adonio Curcio"), Associazione Italiana per la Ricerca sul Cancro (AIRC, project n. 12849/2012), AIRC project Calabria 2011 (http://www.airc.it/) and Fondazione Cassa di Risparmio di Calabria e Lucania. 


\section{Authors' details}

'Department of Pharmacy, Health and Nutritional Sciences, University of Calabria, 87036 Rende (Cosenza), Italy. ${ }^{2}$ Section of Microbiology, University of Brescia, Piazzale Spedali Civili 1, 25123 Brescia, Italy.

Received: 22 March 2013 Revised: 17 June 2013

Accepted: 15 August 2013 Published: 15 August 2013

\section{References}

1. Polyak K, Kalluri R: The role of the microenvironment in mammary gland development and cancer. Cold Spring Harb Perspect Biol 2010, 2:a003244.

2. Bhowmick NA, Neilson EG, Moses HL: Stromal fibroblasts in cancer initiation and progression. Nature 2004, 432:332-337.

3. Kalluri R, Zeisberg M: Fibroblasts in cancer. Nature Rev Cancer 2006, 6:392-401

4. Orimo A, Weinberg RA: Stromal fibroblasts in cancer. Cell Cycle 2006, 5:1597-1601.

5. Gaggioli C, Hooper S, Hidalgo-Carcedo C, Grosse R, Marshall JF, Harrington K, Sahai E: Fibroblast-led collective invasion of carcinoma cells with differing roles for RhoGTPases in leading and following cells. Nat Cell Biol 2007, 9:1392-1400.

6. Shimoda M, Mellody KT, Orimo A: Carcinoma-associated fibroblasts are a rate-limiting determinant for tumour progression. Semin Cell Dev Biol 2009, 21:19-25.

7. Liao D, Johnson RS: Hypoxia: a key regulator of angiogenesis in cancer. Cancer Metastasis Rev 2007, 26:281-290.

8. Harris AL: Hypoxia-a key regulator factor in tumor growth. Nat Rev Cancer 2002, 2:38-47.

9. Rapisarda A, Melillo G: Role of the hypoxic tumor microenvironment in the resistance to anti-angiogenic therapies. Drug Resist Updat 2009, 12:74-80.

10. Lundgren K, Holm C, Landberg G: Hypoxia and breast cancer: prognostic and therapeutic implications. Cell Mol Life Sci 2006, 64:3233-3247.

11. Semenza GL: Defining the role of hypoxia-inducible factor 1 in cancer biology and therapeutics. Oncogene 2010, 29:625-634.

12. Semenza GL: Hypoxia-inducible factors: mediators of cancer progression and targets for cancer therapy. Trends Pharmacol Sci 2012, 33:207-214.

13. Semenza GL: Oxygen sensing, homeostasis, and disease. N Engl I Med 2011, 365:537-547.

14. Semenza GL, Agani F, Booth $G$, Forsythe J, lyer $N$, Jiang $H$, Leung $S$, Roe $R$, Wiener C, Yu A: Structural and functional analysis of hypoxia-inducible factor I. Kidney Int 1997, 51:553-555.

15. Wang GL, Semenza GL: General involvement of hypoxia-inducible factor 1 in transcriptional response to hypoxia. Proc Natl Acad Sci USA 1993, 90:4304-4308.

16. Manalo DJ, Rowan A, Lavoie T, Natarajan L, Kelly BD, Ye SQ, Garcia JG, Semenza GL: Transcriptional regulation of vascular endothelial cell responses to hypoxia by HIF-1. Blood 2005, 105:659-669.

17. Arias-Pulido H, Chaher N, Gong Y, Qualls C, Vargas J, Royce M: Tumor stromal vascular endothelial growth factor $A$ is predictive of poor outcome in inflammatory breast cancer. BMC Cancer 2012, 12:298.

18. Yu L, Deng L, Li J, Zhang Y, Hu L: The prognostic value of vascular endothelial growth factor in ovarian cancer: A systematic review and meta-analysis. Gynecol Oncol 2013, 128:391-396.

19. Recchia AG, De Francesco EM, Vivacqua A, Sisci D, Panno ML, Andò S, Maggiolini M: 2011. The G protein coupled receptor 30 is up-regulated by hypoxia-inducible factor-1alpha (HIF-1alpha) in breast cancer cells and cardiomyocytes. J Biol Chem 2011, 286:10773-10782.

20. Lappano R, Recchia AG, De Francesco EM, Angelone T, Cerra MC, Picard D, Maggiolini M: The cholesterol metabolite 25-hydroxycholesterol activates estrogen receptor a-mediated signaling in cancer cells and in cardiomyocytes. PLoS One 2011, 6:e16631

21. Pandey DP, Lappano R, Albanito L, Madeo A, Maggiolini M, Picard D: Estrogenic GPR30 signalling induces proliferation and migration of breast cancer cells through CTGF. EMBO J 2009, 28:523-532.

22. Chu CY, Chang CC, Prakash E, Kuo ML: Connective tissue growth factor (CTGF) and cancer progression. J Biomed Sci 2008, 15:675-685.

23. Madeo A, Maggiolini M: Nuclear alternate estrogen receptor GPR30 mediates 17beta-estradiol-induced gene expression and migration in breast cancer-associated fibroblasts. Cancer Res 2010, 700:6036-6046.

24. Claycomb WC, Lanson NA, Stallworth BS Jr, Egeland DB, Delcarpio JB, Bahinski A, Izzo NJ Jr: HL-1 cells: a cardiac muscle cell line that contracts and retains phenotypic characteristics of the adult cardiomyocyte. Proc Natl Acad Sci USA 1998, 95:2979-2984.

25. Maggiolini M, Donzé O, Picard D: A non-radioactive method for inexpensive quantitative RT-PCR. Biol Chem 1999, 380:695-697.

26. Albanito L, Sisci D, Aquila S, Brunelli E, Vivacqua A, Madeo A, Lappano R, Pandey DP, Picard D, Mauro L, Andò S, Maggiolini M: Epidermal growth factor induces $\mathrm{G}$ protein-coupled receptor 30 expression in estrogen receptor-negative breast cancer. Endocrinology 2008, 149:3799-3808.

27. Lanzen J, Braun RD, Klitzman B, Brizel D, Secomb TW, Dewhirst MW: Direct demonstration of instabilities in oxygen concentrations within the extravascular compartment of an experimental tumor. Cancer Res 2006, 66:2219-2223.

28. Staton CA, Reed MW, Brown NJ: A critical analysis of current in vitro and in vivo angiogenesis assays. Int J Exp Pathol 2009, 90:195-221.

29. Soares R, Guo S, Gärtner F, Schmitt FC, Russo J: 17 beta-estradiol-mediated vessel assembly and stabilization in tumor angiogenesis requires TGF beta and EGFR crosstalk. Angiogenesis 2003, 6:271-281.

30. Semenza G: Angiogenesis in ischemic and neoplastic disorders. Annu Rev Med 2003, 54:17-28.

31. Ferrara N: Vascular endothelial growth factor: basic science and clinical progress. Endocr Rev 2004, 25:581-611.

32. Semenza GL: Hydroxylation of HIF-1: oxygen sensing at the molecular level. Physiology (Bethesda) 2004, 19:176-182.

33. Smith HO, Leslie KK, Singh M, Qualls CR, Revankar CM, Joste $N E$, Prossnitz ER: GPR30: a novel indicator of poor survival for endometrial carcinoma. Am J Obstet Gynecol 2007, 196:386.e1-386.e11.

34. Smith HO, Arias-Pulido H, Kuo DY, Howard T, Qualls CR, Lee SJ, Verschraegen CF, Hathaway HJ, Joste NE, Prossnitz ER: GPR30 predicts poor survival for ovarian cancer. Gynecol Oncol 2009, 114:465-471.

35. Filardo EJ, Graeber CT, Quinn JA, Resnick MB, Giri D, DeLellis RA, Steinhoff MM, Sabo E: Distribution of GPR30, a seven membranespanning estrogen receptor, in primary breast cancer and its association with clinicopathologic determinants of tumor progression. Clin Cancer Res 2006, 12:6359-6366.

36. Lappano R, Maggiolini M: G protein-coupled receptors: novel targets for drug discovery in cancer. Nat Rev Drug Discov 2011, 10:47-60.

37. Lappano R, Maggiolini M: GPCRs and cancer. Acta Pharmacol Sin 2012, 33:351-362.

38. Lappano R, Rosano C, De Marco P, De Francesco EM, Pezzi V, Maggiolini M: Estriol acts as a GPR30 antagonist in estrogen receptor-negative breast cancer cells. Mol Cell Endocrinol 2010, 320:162-170.

39. Lappano R, Santolla MF, Pupo M, Sinicropi MS, Caruso A, Rosano C, Maggiolini M: MIBE acts as antagonist ligand of both estrogen receptor $a$ and GPER in breast cancer cells. Breast Cancer Res 2012, 14:R12.

40. Santolla MF, Lappano R, De Marco P, Pupo M, Vivacqua A, Sisci D, Abonante S, lacopetta D, Cappello AR, Dolce V, Maggiolini M: G proteincoupled estrogen receptor mediates the up-regulation of fatty acid synthase induced by $17 \beta$-estradiol in cancer cells and cancer-associated fibroblasts. J Biol Chem 2012, 287:43234-43245.

41. Vivacqua A, Romeo E, De Marco P, De Francesco EM, Abonante $S$, Maggiolini M: GPER mediates the Egr-1 expression induced by $17 \beta-$ estradiol and 4-hydroxitamoxifen in breast and endometrial cancer cells. Breast Cancer Res Treat 2012, 133:1025-1035.

42. Pupo M, Pisano A, Lappano R, Santolla MF, De Francesco EM, Abonante S, Rosano C, Maggiolini M: Bisphenol A induces gene expression changes and proliferative effects through GPER in breast cancer cells and cancerassociated fibroblasts. Environ Health Perspect 2012, 120:1177-1182.

43. Lappano R, Rosano C, Santolla MF, Pupo M, De Francesco EM, De Marco P, Ponassi M, Spallarossa A, Ranise A, Maggiolini M: Two novel GPER agonists induce gene expression changes and growth effects in cancer cells. Curr Cancer Drug Targets 2012, 12:531-542.

44. Allinen M, Beroukhim R, Cai L, Brennan C, Lathi-Domenici J, Huang AH, Porter D, Hu Am, Chinh L, Richardson A, Schniff S, Seller WR, Polyak K: Molecular characterization of the tumor microenvironment in breast cancer. Cancer Cell 2004, 6:17-32.

45. Orimo A, Gupta PB, Sgroi DC, Arenzana-Seisdedos F, Delaunay T, Naeem R, Carey VJ, Richardson AL, Weinberg RA: Stromal fibroblasts present in invasive human breast carcinomas promote tumor growth and angiogenesis through elevated SDF-1/CXCL12 secretion. Cell 2005, 121:335-348.

46. Bhowmick NA, Chytil A, Plieth D, Gorska AE, Dumont N, Shappell S, Washington MK, Neilson EG, Moses HL: TGF-beta signaling in fibroblasts 
modulates the oncogenic potential of adjacent epithelia. Science 2004, 303:848-851.

47. Elenbaas B, Weinberg RA: Heterotypic signaling between epithelial tumor cells and fibroblasts in carcinoma formation. Exp Cell Res 2001, 264:169-184.

48. Coussens LM, Werb Z: Inflammation and cancer. Nature 2002, 420:860-867.

49. Cunha GR, Hayward SW, Wang YZ, Ricke WA: Role of the stromal microenvironment in carcinogenesis of the prostate. Int J Cancer 2003, 107:1-10.

50. Olumi AF, Grossfeld GD, Hayward SW, Carroll PR, Tlsty TD, Cunha GR: Carcinoma-associated fibroblasts direct tumor progression of initiated human prostatic epithelium. Cancer Res 1999, 59:5002-5011.

51. Tlsty TD: Stromal cells can contribute oncogenic signals. Semin Cancer Biol 2001, 11:97-104.

52. Vamesu S: Angiogenesis and tumor histologic type in primary breast cancer patients: an analysis of 155 needle core biopsies. Rom J Morphol Embryol 2008, 49:181-188.

53. Vermeulen PB, van Golen KL, Dirix LY: Angiogenesis, lymphangiogenesis, growth pattern, and tumor emboli in inflammatory breast cancer: a review of the current knowledge. Cancer 2010, 116:2748-2754.

54. Veikkola T, Alitalo K: VEGFs, receptors and angiogenesis. Sem Cancer Biol 1999, 9:211-220.

55. Maity A, Sall W, Koch CJ, Oprysko PR, Evans SM: Low pO2 and betaestradiol induce VEGF in MCF-7 and MCF-7-5C cells: relationship to in vivo hypoxia. Breast Cancer Res Treat 2001, 67:51-60.

56. Zhang HT, Craft P, Scott PA, Ziche M, Weich HA, Harris AL, Bicknell R: Enhancement of tumor growth and vascular density by transfection of vascular endothelial cell growth factor into MCF-7 human breast carcinoma cells. J Natl Cancer Inst 1995, 87:213-219.

57. Yoshiji $H$, Harris SR, Thorgeirsson UP: Vascular endothelial growth factor is essential for initial but not continued in vivo growth of human breast carcinoma cells. Cancer Res 1997, 57:3924-3928.

58. Borgstrom P, Gold DP, Hillan KJ, Ferrara N: Importance of VEGF for breast cancer angiogenesis in vivo: implications from intravital microscopy of combination treatments with an anti-VEGF neutralizing monoclonal antibody and doxorubicin. Anticancer Res 1999, 19:4203-4214.

59. Chen L, Endler A, Shibasaki F: Hypoxia and angiogenesis: regulation of hypoxia-inducible factors via novel binding factors. Exp Mol Med 2009, 41:849-857.

60. Ao A, Wang H, Kamarajugadda S, Lu J: Involvement of estrogen-related receptors in transcriptional response to hypoxia and growth of solid tumors. Proc Natl Acad Sci USA 2008, 105:7821-7826.

61. Smith HO, Stephens ND, Qualls CR, Fligelman T, Wang T, Lin CY, Burton E, Griffith JK, Pollard JW: The clinical significance of inflammatory cytokines in primary cell culture in endometrial carcinoma. Mol Oncol 2013, 7:41-54.

62. Patel VH, Chen J, Ramanjaneya M, Karteris E, Zachariades E, Thomas P, Been M, Randeva HS: G-protein coupled estrogen receptor 1 expression in rat and human heart: Protective role during ischaemic stress. Int J Mol Med 2010, 26:193-199.

63. Liu SQ, Tefft BJ, Zhang D, Roberts D, Schuster DJ, Wu A: Cardioprotective mechanisms activated in response to myocardial ischemia. Mol Cell Biomech 2011, 8:319-338.

64. Galanis A, Pappa A, Giannakakis A, Lanitis E, Dangaj D, SandaUzopoulos R: Reactive oxygen species and HIF-1 signalling in cancer. Cancer Lett 2008, 266:12-20.

65. Gao P, Zhang H, Dinavahi R, Li F, Xiang Y, Raman V, Bhujwalla ZM, Felsher DW, Cheng L, Pevsner J, Lee LA, Semenza GL, Dang CV: HIFdependent antitumorigenic effect of antioxidants in vivo. Cancer Cell 2007, 12:230-238.

66. Dewhirst MW, Cao Y, Moeller B: Cycling hypoxia and free radicals regulate angiogenesis and radiotherapy response. Nat Rev Cancer 2008, 8:425-437.

67. Benizri $E$, Ginouvès $A$, Berra $E$ : The magic of the hypoxia-signaling cascade. Cell Mol Life Sci 2008, 65:1133-1149.

68. Lappano R, De Marco P, De Francesco EM, Chimento A, Pezzi V, Maggiolini M: Cross-talk between GPER and growth factor signaling. Steroid Biochem Mol Biol 2013.

doi:10.1186/bcr3458

Cite this article as: De Francesco et al:: HIF-1 $\alpha /$ GPER signaling mediates the expression of VEGF induced by hypoxia in breast cancer associated fibroblasts (CAFs). Breast Cancer Research 2013 15:R64.

\section{Submit your next manuscript to BioMed Central and take full advantage of:}

- Convenient online submission

- Thorough peer review

- No space constraints or color figure charges

- Immediate publication on acceptance

- Inclusion in PubMed, CAS, Scopus and Google Scholar

- Research which is freely available for redistribution 